\title{
La inundación de Tortosa de octubre de 1787: extremismo hidrometeorológico, catástrofe y gestión de la emergencia en la fachada mediterránea española durante el siglo xvIII
}

The Tortosa flood of October 1787: hydrometeorological extremism, catastrophe and emergency management in the Spanish Mediterranean basin during the 18th century

La inundació de Tortosa d'octubre de 1787: extremisme hidrometereològic, catàstrofe i gestió de l'emergència a la façana mediterrània espanyola durant el segle XVIII

Armando Alberola Romá

\section{Resumen}

Los días 8 y 9 octubre de 1787, Tortosa sufrió la peor de las inundaciones conocidas hasta esa fecha. La provocaron el gran caudal que llevaba el río Ebro y el fortísimo temporal que se abatió sobre su tramo final y desembocadura. El desastre fue terrible, y la ciudad y su entorno estuvieron sumergidos bajo las aguas durante días. En este artículo se estudian las circunstancias que provocaron este suceso extremo, sus consecuencias, la gestión de la catástrofe por parte de los diferentes responsables político-administrativos y la respuesta del Estado.

Palabras clave: siglo xviI, riesgo, sequía, avenidas, inundaciones, catástrofe, gestión política, ayuntamiento, Consejo de Castilla.

\footnotetext{
Abstract

On 8-9 October 1787, Tortosa suffered the worst flooding known to date in the area. It resulted from the great flow of the Ebro River and the very heavy storm that hit its final sec-

1. ORCID: 0000-0002-3238-9239. Universidad de Alicante. Correo electrónico: armando.alberola@ua.es.

Este estudio forma parte de los resultados del proyecto HAR2017-82810-P, incluido en el Programa Estatal de Fomento de la Investigación Científica y Técnica de Excelencia promovido y financiado por el Ministerio de Ciencia, Innovación y Universidades (Gobierno de España) y la Agencia Estatal de Investigación.

Recibido: IV/2021. Evaluado VII/2021. Versión definitiva: VIII/2021.
} 
tion and mouth. The disaster was terrible and the city and its surroundings were submerged under water for days. This article studies the circumstances that caused this extreme event, its consequences, the management of the catastrophe by the different political-administrative officials and the reaction of the State.

Keywords: 18th century, risk, drought, avenues, floods, catastrophe, political management, town hall, Council of Castile.

\section{Resum}

Els dies 8 i 9 d'octubre de 1787, Tortosa va patir la pitjor de les inundacions conegudes fins aquella data. La van provocar el gran cabal del riu Ebre i el fortíssim temporal que va caure sobre el seu tram final i desembocadura. El desastre fou terrible, i la ciutat i el seu entorn van estar submergides sota les aigües durant dies. En aquest article s'estudien les circumstàncies que van provocar aquest esdeveniment extrem, les seves conseqüències, la gestió de la catàstrofe per part dels diferents responsables politico-administratius i la resposta de l'Estat.

Paraules Clau: segle xvII, risc, sequera, inundacions, catàstrofe, gestió política, ajuntament, Consell de Castella.

\section{Introducción}

El Memorial Literario correspondiente a octubre de 1787 daba noticia de la «catástrofe fatal» padecida por Tortosa en los días 8 y 9 de ese mes como consecuencia de la conjunción de una gran crecida del río Ebro con una importante perturbación atmosférica cuyas intensísimas precipitaciones inundaron la ciudad y numerosas poblaciones del curso bajo del río hasta el mar. ${ }^{2} \mathrm{Ni}$ la Gaceta de Madrid, ni el Mercurio Histórico y Político, periódicos oficiales, se hicieron eco del suceso.

El desastre mereció la atención inmediata de los contemporáneos. Los responsables del gobierno ciudadano actuaron con diligencia; también lo hicieron las comunidades religiosas instaladas en la ciudad, diversos funcionarios de la Corona, las tropas allí acantonadas y los profesionales de diferentes oficios que atendieron del mejor modo posible, y en condiciones muy difíciles, las urgencias humanas y materiales e intentaron poner orden en el caos que se produjo. Los primeros, además de las acciones perentorias encaminadas a salvar vidas y proteger todo tipo de bienes afectados, se aplicaron a la tarea de recopilar información - lo más precisa posible_- del alcance de la catástrofe para, de in-

2. Memorial literario, instructivo y curioso de la corte de Madrid, tomo 12, octubre de 1787, parte primera, núm. 47, pp. 269-273. 
mediato, redactar memoriales y súplicas destinados a las diferentes instancias políticas superiores.

Este estudio se basa en fuentes documentales de carácter oficial conservadas en la sección Consejos del Archivo Histórico Nacional. ${ }^{3}$ Es precisamente esta documentación la que suele proporcionar información minuciosa de cualquier desastre climático, hidrometeorológico, geológico o biológico sucedido en los siglos modernos. También lo hace la de procedencia privada - como, por ejemplo, dietarios, correspondencia, crónicas y similares-, idónea para complementar los contenidos de la anterior (Alberola y Mas 2016: 4160). La documentación oficial suele conformar expedientes muy voluminosos, cuyo análisis permite determinar, al margen de los pormenores referidos al suceso de consecuencias catastróficas, algo que ya ha sido indicado líneas más arriba: las iniciativas tomadas desde el primer momento por quienes las sufrieron directamente, los informes, relaciones y peticiones que se elaboraron y remitieron a las diferentes instancias políticas de la monarquía, la respuesta que se les dio y si esta fue rápida y eficaz; también si existieron medidas de prevención derivadas de la reiteración en el tiempo de ese tipo de acontecimiento, si se activaron alarmas y pautas de actuación, si tras el desastre se plantearon iniciativas para evitarlo en el futuro, etc. Lo cual conduce, en última instancia, a interrogarse acerca del grado de improvisación con el que se afrontaba este tipo de situaciones y la existencia - o node lo que hoy en día denominaríamos «protocolos» que aplicar en cada desastre.

Alguna experiencia había ya al respecto en el siglo xviII, pero tuvo que ver más con el impacto de movimientos sísmicos como los que en 1748 y 1755 obligaron a elaborar un modelo de «pesquisa» adaptado a la especificidad de estos para actuar en consecuencia (Alberola 2019a; Alberola 2019b). En lo tocante a los sucesos extremos de causa hidrometeorológica y consecuencias funestas, y pese a que estos se encadenaron durante la centuria con frecuencias cada vez más cortas y destructivas, se optó por resolverlos según las circunstancias de cada momento. Por ello - y aunque la preocupación en los órganos de decisión de la monarquía fue más que evidente dado el gran impacto que ocasionabanno podemos decir que llegaran a recibir un tratamiento homogéneo. Es cierto, no obstante, que desde comienzos del siglo ilustrado se mejoró la rapidez de circulación de la información que, partiendo de las poblaciones afectadas, tenía como destino el Consejo de Castilla, auténtico órgano de gobernación interior del reino, tras pasar el filtro de las intendencias, capitanías generales y audiencias. Precedentes significativos de ello podrían ser, por ejemplo, las inundaciones padecidas por la ciudad de Valencia en los otoños de 1731, 1776 y, sobre todo, 1783; así como otras situaciones similares vividas en el ámbito meridional mediterráneo durante el último cuarto del siglo xviI (Alberola 2010: 100-103, 125-163, 182186; García Torres 2011: 103-120; 2016: 215-235; 2018).

En este sentido, resultaba crucial el papel desempeñado desde el primer momento por las autoridades políticas de los lugares afectados para comprobar si la «respuesta» que dieron a los problemas sobrevenidos resultó acorde con las exigencias del momento; normalmente de extrema urgencia y cargadas de intenso dramatismo. Todo ello, sin olvidar los

3. Se trata de los legajos $23587,37156,37160$ y 37169 . 
factores de riesgo del territorio, el contexto climático y cronológico y, por supuesto, las condiciones sociopolíticas y económicas de la población o poblaciones afectadas.

En el caso de la riada e inundación de Tortosa de octubre de 1787, conocida por sus efectos catastróficos, los estudios de que disponemos - salvo alguna excepción a la que me referiré- se han nutrido habitualmente de fuentes impresas de carácter cronístico que, por lo general, no refieren la procedencia de los datos que manejan. De ahí que, al objeto de garantizar la veracidad de lo que afirman, no resulta extraño que sus autores invoquen -como hace, por ejemplo, Daniel Fernández y Domingo— la consulta de «informes detallados que hemos visto» pero de los que no se indica ni el contenido ni su localización (Fernández y Domingo 1867: 295). Otros, sin embargo, como el canónigo de la catedral Ramón O'Callagham, escribe en sus Anales de Tortosa que, para referir la inundación, resumió dos relaciones que se imprimieron en la época "para perpetua memoria». Una, por cuenta del ayuntamiento, «de la que se conserva un ejemplar en el archivo de la catedral»; la otra, a cargo del cabildo, se hallaba inserta «en el libro de actas de 1787» (O'Callagham 1886:127). ${ }^{4}$ Sin embargo, al computar las muertes y las casas destruidas por la inundación en la ciudad y poblaciones de su entorno O'Callagham se limita a señalar que sus datos proceden «de un estado oficial que hemos visto» (1886: 131).

Pese a todo, el cotejo de estas descripciones cronísticas con la información proporcionada por la documentación oficial no llega a ofrecer discrepancias sustanciales en lo que al relato del suceso se refiere, aunque la segunda permite ahondar en los asuntos y efectuar precisiones imprescindibles; aspectos estos que suelen brillar por su ausencia en las crónicas. La exhumación y tratamiento de este tipo de expedientes permiten confirmar, precisar o rebatir alguna que otra afirmación que, por repetida, ha llegado a alcanzar la consideración de indubitable.

Lo más relevante de la documentación procedente de archivo, en este caso el expediente que promovió el Consejo de Castilla a instancias de la ciudad de Tortosa, es que su análisis desvela detalles poco o nada conocidos; sobre todo, y entre otros, los relativos a la gestión política del asunto, a los evidentes «roces» que existieron entre las instituciones - caso del capitán general y presidente de la Real Audiencia con el ayuntamiento tortosino-, al papel fundamental desempeñado por la intendencia o el fiscal del Consejo de Castilla a la hora de calificar el suceso y de establecer el alcance de las hipotéticas ayudas, o al conocimiento de la desgracia que, de manera directa, tuvieron personalidades como el conde de Campomanes, en su condición de gobernador interino del Consejo de Castilla, el conde de Floridablanca, titular de la primera Secretaría de Estado e, incluso, el propio Carlos III. ${ }^{5}$

4. Sin duda se refiere a una de las copias de la Relación de lo acontecido en la ciudad de Tortosa con la Ynundación del río Ebro que empezó el día 8 de octubre de este corriente año 1787, elaborada a lo largo del mes de octubre y que fue remitida a diferentes instancias oficiales a partir del 14 de noviembre; en Archivo Histórico Nacional (AHN), Consejos, legajo 23587 , ff. 56-67v, ff. 73-83v, ff. 87-93 y ff. 98-109.

5. AHN, Consejos, legajo 23587, Expediente promovido en el Consejo a representaciones del Governador, Ayuntamiento y Alcalde Mayor de la ciudad de Tortosa con motivo de los extragos causados por el río Ebro en aquella ciudad y pueblos de su comarca, por la furiosa abenida de Agua acaecida el día 8 de octubre de este año de 1787. 


\section{Tortosa inundada: el contexto climático}

Resulta imprescindible prestar especial atención a las circunstancias atmosféricas en las que se produjo esta riuada grossa de Tortosa, considerada la más destructiva de todas las padecidas en su historia (Balasch et al. 2019; Barriendos et al. 2019; Ollero 1996; Barriendos 1995). Debo añadir, asimismo, que casi un año después, a comienzos de septiembre de 1788, la ciudad del Delta volvería a soportar una nueva crecida del Ebro — con la consiguiente inundación - tras otro imponente temporal que afectó a todo el actual Campo de Tarragona (Alberola 2010: 200-203), circunstancia que aún se repetiría en $1789 .^{6}$

Desde el punto de vista hidrometeorológico, la década de los ochenta del siglo xviI resultó muy inestable y compleja (Alberola y García Acosta 2021: 55-94; García Torres 2018; Alberola 2014: 208-225). Inserta en la fase crítica de la «oscilación Maldá», cuyo extremismo es bien conocido, a la pertinaz sequía que desde mediados de la centuria castigaba a buena parte de la península ibérica se añadieron precipitaciones de frecuencia e intensidad excepcionales que provocaron grandes riadas e inundaciones (Barriendos y Llasat 2009).

La aludida inestabilidad fue la nota dominante durante el año 1787. A mitad de enero hubo infrecuentes e intensas precipitaciones en Cataluña, que provocaron las crecidas del Francolí y del Besós, entre otros ríos. El primero inundó Tarragona y rompió su puente. El caudal del segundo - tan incrementado que durante cinco días no se pudo cruzar-anegó toda su cuenca y provocó importantes estragos en campos e infraestructuras hidráulicas, el derrumbe de casas, el destrozo de carreteras y caminos y un número indeterminado de muertos (Alberola 2010: 196-200). Casi simultáneamente, fuertes vientos del sur y sudeste castigaron las costas catalanas y causaron naufragios (Alberola y Pradells 2012: 72-74).

El verano de ese año fue muy caluroso y salpicado de fuertes tormentas. En la última semana de septiembre descargaron chubascos muy intensos en la cuenca alta del río Ebro que provocaron una importante crecida de su afluente, el Aragón el cual, tras desbordarse, destruyó buena parte de los puentes que lo cruzaban y asoló las poblaciones y campos de sus riberas. La peor parte se la llevó Sangüesa que, en la noche del 24 al 25 de septiembre, vio cómo las aguas del río rompían su muralla, inundaban con rapidez el casco urbano y ocasionaban la muerte en apenas tres horas de 587 de sus habitantes; ${ }^{7}$ una tragedia de la que informó el Memorial Literario en sus páginas. ${ }^{8}$ A la vista de la secular reiteración de estos sucesos, se proyectó el traslado de la ciudad a un lugar más seguro, aunque su coste económico obligó a desestimarlo (Sambricio 1991: 563-565; Merino 1981: 259).

Los días 28 y 29 de septiembre, un violento temporal acompañado de granizo se abatió sobre Cullera y otros pueblos de la Albufera valenciana, destruyendo la cosecha de arroz. ${ }^{9}$ En su desplazamiento hacia el norte, descargó con fuerza sobre la Plana de Caste-

6. La documentación, en Archivo Histórico Nacional (AHN), Consejos, legajo 37160, sept. 7, s.f.; y sept. 22, s.f.

7. Toda la documentación archivística relativa a este suceso se puede consultar en el enlace http://www.historiade sanguesa.es/historia.htm, en el apartado correspondiente a Inundaciones. La gran inundación de 1787.

8. Memorial Literario, tomo 12, octubre de 1787, parte primera, núm. 57, pp. 354-359.

9. AHN, Consejos, legajo 37336; Archivo General de Simancas (AGS), Secretaría y Superintendencia de Hacienda, legajos 580 y 586). 
llón y destrozó su huerta la víspera de San Miguel (Rocafort [1762-1818] 1945: 52-54). Lo peor llegaría en la primera semana de octubre en forma de importante perturbación atmosférica estudiada sinópticamente por Mariano Barriendos gracias a las observaciones meteorológicas recogidas por médicos, astrónomos o, simplemente, curiosos contemporáneos (Barriendos 2005: 21-23).

Desde finales de septiembre, un fuerte anticiclón situado en Rusia interrumpió la habitual circulación de borrascas atlánticas. Una de estas quedó fija sobre la península ibérica donde, alimentada por vientos húmedos mediterráneos de componente este y sudeste empujados por el anticiclón, provocó el desencadenamiento de intensísimas precipitaciones sobre la mitad oriental de la península, un territorio con un sistema fluvial condicionado por su quebrada orografía, que convierte los pequeños cursos próximos a la costa en peligrosos torrentes capaces de arrasar con todo lo que se interponga en su paso (Barriendos 2005: 21-23; Balasch et al. 2019). Normalmente, cuando se producen estas lluvias de alta intensidad horaria, los grandes ríos son capaces de distribuir mejor sus crecidas en el tiempo y evitar la concentración de grandes caudales de manera simultánea. No fue el caso durante los primeros diez días de octubre de 1787: la larga e inhabitual duración de esta perturbación produjo desbordamientos extraordinarios de los ríos Ebro y Segre, entre otros muchos, de consecuencias catastróficas.

Tortosa y las poblaciones del curso bajo del primero de ellos serían las principales afectadas por esta perturbación, pero no las únicas. Algo más al sur, una gran crecida del río Millars destruyó el puente de Onda y todos los molinos hasta la confluencia con la Rambla de la Viuda, muy incrementada por los aportes del río Montlleó (Alberola 2010: 197199; Benito et al., 2020). A partir de este punto, el ímpetu de las aguas en dirección al mar derrumbó el puente de Adzeneta y arrastró árboles, materiales de todo tipo, animales y personas hasta el término de Almassora. La ruina de este puente, que unía Adzeneta con Benafigós, aisló a una docena de poblaciones y cortó las comunicaciones con Aragón y Cataluña. ${ }^{10}$ Un informe del gobernador de Lleida remitido el 11 de octubre al Consejo de Castilla daba cuenta de que, tras varios días de intensas precipitaciones, el 7 «todos los ríos de esta comarca salieron de madre», provocando al siguiente una gran crecida del Segre que, aunque no llegó a destruir el puente de la localidad, determinó la pérdida de las cosechas y la rotura de los sistemas de riego. ${ }^{11}$

\section{Salió el Ebro de madre a deshora de la noche: relato -breve- del desastre}

El desastre vivido por Tortosa se puede estudiar con detalle gracias a la documentación conservada en el Archivo Histórico Nacional. También, y como he indicado, gracias a tra-

10. AHN, Consejos, legajo 22782; asimismo Rocafort, 1945: 53.

11. AHN. Consejos, legajo 37156, oct. 14. El gobernador de la ciudad de Lérida da cuenta de los estragos ocurridos en aquella ciudad con motivo de las avenidas de los ríos inmediatos ocurridas el día 8 de octubre del año 1787. 
bajos que descansan en otro tipo de fuentes. Es cierto que este episodio de consecuencias catastróficas ocupó no solo la atención de las autoridades competentes; se hicieron eco asimismo el Memorial Literario, contemporáneos interesados (Aparicio 1788; Pelfort 1788; García Zamora 1804) así como cronistas decimonónicos y de la primera mitad del siglo xx (Fernández y Domingo 1867; O'Callagham 1886; Pastor 1901; Bayerri 1934-1989; Brú 1955). Unos y otros escribieron sus impresiones sobre esta riada en papeles e impresos sueltos o incluyeron comentarios en sus Anales e Historias que, en buena medida, han servido de base a trabajos más recientes. La monografía de Ramón Miravall sobre los desastres de causa natural padecidos por Tortosa y su área de influencia a lo largo de su historia (1997) es la que ofrece el relato más documentado y preciso de esta riada e inundación merced al análisis de diferente documentación, fundamentalmente impresa (Miravall 1997: 72-88). Sirve de imprescindible y adecuado complemento el estudio de Enric Querol sobre los textos a que dio lugar el calamitoso suceso (2006).

A comienzos de octubre de 1787, las aguas del Ebro bajaban muy caudalosas hacia su desembocadura como consecuencia de las intensas y reiteradas precipitaciones que descargaron sobre su curso alto y medio. A su llegada a Tortosa coincidieron con el desencadenamiento del violento temporal indicado líneas atrás dando lugar a una inundación de proporciones hasta entonces desconocidas. En Flagells naturals sobre Tortosa, Ramón Miravall describe con precisión la catástrofe que se abatió sobre la ciudad y poblaciones de su entorno: la llegada el día 8 de octubre de un Ebro mucho más crecido de lo recordado en sus peores momentos, las intensas y persistentes precipitaciones que se le añadieron, la rotura del puente de barcas que unía las dos partes del casco urbano, el constante crecimiento del nivel de las aguas en medio de la oscuridad de la noche hasta alcanzar alturas jamás acreditadas, la huida de los vecinos de sus domicilios en busca de lugares elevados o, en su defecto, refugio en los pisos altos, azoteas, tejados o árboles en espera de ayuda, el hundimiento de edificios, la inundación de los arrabales y huerta, las medidas de urgencia decretadas por los responsables municipales para atender a los vecinos, apuntalar casas y liberar obstáculos de las calles convertidas en auténticos ríos, el acogimiento de los damnificados en edificios religiosos y civiles, el suministro de alimentos, etc. (Miravall 1997: 72-78; Muñoz 2014-2015).

En la documentación oficial, tanto en la que podríamos considerar estricta correspondencia administrativa como en los informes y relaciones elaborados al efecto y adjuntados, proliferan descripciones y comentarios que intentan transmitir con gran realismo y sin escatimar recursos retóricos la furia de los elementos desatados, vinculándola a un segundo diluvio universal y al providencialismo característico de la época. Así, según reza textualmente en la Relación de lo acontecido que el Ayuntamiento de Tortosa comenzaría a remitir a las diferentes autoridades a partir del 14 de noviembre, el desastre se produjo:

Con motivo de la imponderable, nunca vista y copiosa lluvia, acompañada de viento al sur, relámpagos y truenos con que parecía querer la divina Providencia por segunda vez castigar con agua los pecados de 
los hombres, salió el Barranco del Rastro por la puerta superior y entrando por la ciudad cortó enteramente la comunicación entre una y otra eminencia. ${ }^{12}$

El agua alcanzó los 38 palmos en muchas partes del casco urbano; aunque en los arrabales superó con creces esa altura. Las autoridades no se atrevieron a aventurar las «muchas varas que llevaría el Ebro en el centro de su cauce», aunque sí recurrieron al comentario que, habitualmente, se empleaba en estos casos: «No hay memoria en la tradición, ni en los documentos antiguos referentes a otras avenidas que llegase de mucho a la actual». ${ }^{13}$

Los peores momentos se vivieron entre la tarde noche del día 8, el día 10 y el 12, aunque «con corta diferencia comenzaron a manifestarse los terrenos más altos de la huerta». No sería hasta el 16, sin embargo, cuando «ciñó el Ebro sus caudales a los límites de su antiguo alveo, quedando no obstante los sitios hondos encharcados y formando en la ribera lagunas considerables». ${ }^{14}$

Un informe del Real Acuerdo remitido al conde de Campomanes a finales de noviembre - tras reelaborar la Relación recibida del ayuntamiento, incorporarle datos nuevos y mudarle el nombre por el de Noticia ${ }^{15}$ destacaba que «investigadas» las inundaciones padecidas por Tortosa en siglos anteriores no había duda de que «las mayores de que se halla memoria [habían sido] mucho menores que la últimamente acaecida». Y concretamente aludía a las de 1448 y 1582, de cuyo impacto daban fe sendas inscripciones que figuraban en la puerta de la ciudad próxima al puente de barcas, a la vez que insistía en que «estas avenidas fueron menores y casi momentáneas, comparadas con la altura y duración que ha tenido esta». ${ }^{16}$ También la de 1787 era mayor que las de 1617 y 1743 , «de cuia memoria se conservan aun inscripciones circunstanciadas en algunos parajes de la ciudad». En cualquier caso, a ninguna de estas cuatro «acompañaron los funestos acontecimientos que esta presente»; ${ }^{17}$ de ahí el tremendo impacto dejado por esta, pues los daños y pérdidas fueron cuantiosos y muy graves. Estudios recientes estiman en 12.900 metros cúbicos por segundo el pico máximo de descarga del caudal del Ebro y una altura de las aguas de 8,7 metros sobre el nivel de estiaje en Tortosa (Barriendos 1995: 68) y próxima a los 10 metros en la escala que figura adosada al muro de la iglesia de San Martín de Xerta (Balasch et al. 2018: 653-654). Al amanecer del día 9 de octubre, y según se podía leer en la ya aludida Relación,

[...] representaba la ciudad, arrabales y campiña de Tortosa el más triste espectáculo, en cuya narrativa será diminuta cualquiera exageración, que tal vez parecerá a los que no lo presenciaron incurrir en el vi-

12. Relación de lo acontecido en la ciudad de Tortosa con la Ynundación del río Ebro que empezó el día 8 de octubre de este corriente año 1787, AHN, Consejos, legajo 23587, f. 57.

13. Ibid., f. $58 \mathrm{v}$.

14. Ibid., ff. 61-62.

15. Noticia de lo acaecido en Tortosa con la inundación del Ebro que empezó el 8 de octubre, AHN, Consejos, legajo 23587, ff. 87-87v.

16. Ibid.

17. Inscripciones sobre la riada en Miravall (1996: 83-86) y Muñoz (2014-2015: 261). 
cio de hipérbole afectada. [...] de monte a monte no hay más de media legua de distancia; todo era río, con una columna de agua imponderable y nunca oída en Tortosa, que solo dignamente puede esta compararse con un alto desbordamiento del Nilo en los feraces campos de Egipto. ${ }^{18}$

En estas circunstancias, y según avanzaban los días, las desgracias se acumulaban, se iban conociendo los pormenores de la calamidad y tomaba forma un corpus informativo que serviría de base para la elaboración de memoriales, demandas y súplicas. ${ }^{19}$ Casi tres millares de personas privadas de todos sus bienes encontraron acogida en conventos, colegios de religiosos y cuarteles. El ayuntamiento ordenó el acopio y distribución de víveres, sin aumento de precio, y diversas instituciones civiles y religiosas, así como poblaciones cercanas, prestaron de inmediato ayuda solidaria con alimentos y limosnas. También se dispuso lo necesario para, entre otras cosas, garantizar el orden público y evitar robos.

Con el fin de poder dar cuenta de manera resumida del alcance humano y económico de la catástrofe, se han elaborado tres cuadros-resumen. Para formarse una idea del mismo bástese indicar que, a finales del mes de noviembre, las pérdidas globales que se comunicaron oficialmente a las autoridades se estimaron en 2.672.576 libras; de las que 1.428.852 libras, 10 sueldos y 4 dineros correspondían a Tortosa y las restantes 1.243.725 libras y 1 sueldo a las poblaciones la ribera del Ebro. ${ }^{20}$ En estas cantidades se incluían los edificios arruinados, el valor en metálico de todos los productos agrícolas almacenados y perdidos, así como el de las tierras de labor arrasadas por las aguas y convertidas en improductivas, la reparación de infraestructuras hidráulicas, de riego y de comunicación, muebles y «alhajas».

Aunque las diferentes fuentes no llegan a coincidir plenamente, el total de casas arruinadas por la inundación pudo rondar las 1.180 —de ellas, 299 en Tortosa—, a las que se añadirían 69 fábricas y 28 casas del común en diferentes poblaciones; sin contar las más de 750 que debieron ser apuntaladas (véase cuadro 3). Los muertos ascendieron a 183, aunque Miravall aventura también la cifra de 185 (Miravall 1997: 76). También se observa cierto desfase en el desglose de fallecidos por arrabales. Para auxiliar a los damnificados y contribuir en la reconstrucción, Carlos III instituyó una Junta de Caridad y concedió una exención en el pago de impuestos durante cuatro años; aspectos que trataré más adelante.

18. Relación de lo acontecido en la ciudad de Tortosa con la Ynundación del río Ebro (...), f. 60v.

19. Un seguimiento detallado en Expediente promovido en el Consejo a representaciones del Governador, Ayuntamiento y Alcalde Mayor de la ciudad de Tortosa con motivo de los extragos causados por el río Ebro en aquella ciudad y pueblos de su comarca, por la furiosa abenida de Agua acaecida el día 8 de octubre de este año de 1787, AHN, Consejos, legajo 23587. Asimismo, Miravall, 1997.

20. Se trataba de Amposta, Aldover, Xerta Tibenys, Benifallet, Ginestar, Miravet, Benissanet, Mora, Asçó, Flix, Ribarroja y El Borrás; cf. en Estado que manifiesta los daños que han padecido los pueblos del corregimiento de Tortosa situados sobre la Ribera de Ebro de resultas de la crecida del río en la noche del día ocho de octubre anterior, visto y reconocido por Don Luis de la Cuesta en virtud de orden del Capitán General del Principado, tasado todo a juicio prudente de Peritos con asistencia de la Justicia en su respectivo pueblo [...]. Tortosa 22 de Noviembre de 1787. Dn. Luis de la Cuesta, AHN, Consejos, legajo 23587, f. 86. Los datos correspondientes a la ciudad figuraban en la ya aludida Relación. Miravall utiliza un impreso de «difícil localización» pero cuyos datos deben estar extraídos del original al que aludo. 


\section{Cuadro 1}

Edificios arruinados y apuntalados en la ciudad de Tortosa y poblaciones del curso bajo del río Ebro como consecuencia de la riada e inundación de octubre de $\mathbf{1 7 8 7}$

\begin{tabular}{|l|r|r|r|r|r|r|r|}
\hline POBLACIÓN & C. A. C. U. & C. A. AyH. & C. AP. & C. C. A. & F. A. & \multicolumn{2}{|c|}{$\begin{array}{l}\text { TOTALES } \\
\text { Arruinadas }\end{array}$} \\
\hline Tortosa & 98 & 201 & + de 400 & - & - & 299 & 400 \\
\hline Amposta & - & 10 & 2 & - & - & 10 & 2 \\
\hline Aldover & - & 33 & - & - & - & 33 & - \\
\hline Xerta & 108 & 2 & 71 & 2 & - & 112 & 71 \\
\hline Tivenys & 3 & 35 & 26 & - & 23 & 61 & 26 \\
\hline Benifallet & 31 & - & 74 & 4 & 8 & 43 & 74 \\
\hline Ginestar & 53 & 70 & 85 & 2 & 1 & 126 & 85 \\
\hline Miravet & 60 & 27 & 53 & 2 & 11 & 100 & 53 \\
\hline Benissanet & 102 & 173 & 12 & 8 & 7 & 290 & 12 \\
\hline Mora & 40 & 64 & 32 & 9 & 10 & 123 & 32 \\
\hline Ascó & 23 & 4 & - & - & 6 & 33 & - \\
\hline Flix & - & 33 & - & - & 2 & 35 & - \\
\hline Riba-roja & - & 14 & - & 1 & 1 & 16 & - \\
\hline TOTALES & $\mathbf{5 1 8}$ & $\mathbf{6 6 6}$ & $\mathbf{+ d e} \mathbf{7 5 5}$ & $\mathbf{2 8}$ & $\mathbf{6 9}$ & $\mathbf{1 . 2 8 1}$ & $+\mathbf{d e} \mathbf{7 5 5}$ \\
\hline
\end{tabular}

Fuentes: elaboración propia y Relación de lo acontecido en la ciudad de Tortosa con la Ynundación del río Ebro que empezó el día 8 de octubre de este corriente año 1787, Noticia de lo acaecido en Tortosa con la inundación del Ebro que empezó el 8 de octubre, Estado que manifiesta los daños que han padecido los pueblos del corregimiento de Tortosa situados sobre la Ribera de Ebro [...], visto y reconocido por Don Luis de la Cuesta [...]. AHN, Consejos, legajo 23587.

Claves: C. A. C. U = casas arruinadas en el casco urbano; C. A. AyH. = casas arruinadas en arrabales y huerta; C. AP. $=$ Casas apuntaladas; C. C. A. = casas del común arruinadas; F. A. = fábricas arruinadas. 


\section{Cuadro 2}

\section{Fallecidos en Tortosa y poblaciones de la Ribera del Ebro en la inundación de octubre de $\mathbf{1 7 8 7}$}

\begin{tabular}{|c|c|lc|}
\hline POBLACIÓN & FALLECIDOS & \multicolumn{2}{|c|}{ DETALLES } \\
\hline \multirow{3}{*}{ Tortosa } & & Casco urbano & 3 \\
& & Raval de la Creu & 27 \\
& & Raval de Jesús & 26 \\
& & Horta del Temple & 10 \\
& & Partida de Bítem & 8 \\
& & TOTAL & $74^{*}$ \\
\hline \multirow{3}{*}{ Pueblos de la Ribera del Ebro } & & Xerta & 29 \\
& & Tivenys & 2 \\
& & Benifallet & 1 \\
& & Ginestar & 3 \\
& & Miravet & 1 \\
& & Benissanet & 53 \\
& & Mora d'Ebre & 9 \\
& & TOTAL & 98 \\
\hline
\end{tabular}

Fuentes: elaboración propia y Relación de lo acontecido en la ciudad de Tortosa con la Ynundación del río Ebro que empezó el día 8 de octubre de este corriente año 1787, Noticia de lo acaecido en Tortosa con la inundación del Ebro que empezó el 8 de octubre, Estado que manifiesta los daños que han padecido los pueblos del corregimiento de Tortosa situados sobre la Ribera de Ebro [...], visto y reconocido por Don Luis de la Cuesta [...], AHN, Consejos, legajo 23587.

*Esta información de 74 fallecidos en Tortosa, sus arrabales y huerta la proporciona Miravall (1997: 81), siguiendo a Fernández (1867) y O'Callaghan (1886). Existe un desfase de 11 personas respecto de los recuentos oficiales.

**Miravall (1997: 81) advierte que Pastor (1901) incrementa en dos el número total de fallecidos.

\section{De Tortosa a Madrid, pasando por Barcelona: la gestión de la desgracia}

El 10 de octubre de 1787, tras soportar durante dos días una situación límite, los miembros del ayuntamiento tortosino encabezados por su alcalde mayor, por un lado, y el gobernador-corregidor Diego de Brias (o Bryas) por otro, enviaban a Barcelona sendos escritos destinados al intendente de Cataluña, barón de La Linde. ${ }^{21}$ Ambas misivas referían, con brevedad no exenta de la angustia que exigía la urgencia del momento, «la furiosa avenida del río Ebro» que, desde las nueve de la noche del día 8, había dejado «enteramente

21. El Ayuntamiento de la ciudad de Tortosa al barón de La Linde, Tortosa, 10 de octubre de 1787; Don Diego de Brias al barón de La Linde, Tortosa, 10 de octubre de 1787. Ambas cartas, respectivamente, en AHN, Consejos, legajo 23587, ff. 4-4v y ff. 5-6. 
inundada esta ciudad y el territorio que comprehenden sus huertas de monte a monte». A la crecida del río se habían añadido «los horrores de una tremenda tempestad que aumentaron la inminencia de los riesgos que hacía por entonces casi imposibles los socorros».22

Manuel Antonio Terán Bustamante y Álvaro de los Ríos, barón de La Linde desde abril de 1738, era a la sazón titular de la Intendencia del Ejército y Principado de Cataluña, previo disfrute de un largo período de interinidad iniciado en 1776 que concluyó en 1785, tras recibir en propiedad el cargo (Escartín 1980: 263-265; Ozanam 175). La máxima autoridad política en Tortosa, pese a su avanzada edad y ya escasa capacidad para el manejo de los asuntos ciudadanos, recaía por entonces en Diego de Brias, mariscal de campo y corregidor-gobernador desde 1775 (Irles 2003: II, 443). El deterioro físico del corregidor ya lo había advertido al conde de Floridablanca en febrero de 1785 el médico José de Masdevall y así lo confirman diferentes comentarios que Nicolás Campaner y Sastre de la Gineta, alcalde mayor de Tortosa sobre cuyos hombros recayó gran parte del peso de la gestión del desastre, desliza en la documentación oficial en la que, en no pocas ocasiones, la firma de Brias está ausente.

El barón de La Linde remitió sin dilación el día 13 de octubre ese par de cartas al Consejo de Castilla a través de Juan de Membiela, Contador General de Propios y Arbitrios de todos los pueblos del Reino, para que se incoara el correspondiente expediente y se dictaran las providencias oportunas. ${ }^{23}$ Con ello se iniciaba una activa correspondencia entre las autoridades tortosinas y los responsables de las instituciones del Principado, el Consejo de Castilla, el propio monarca y significados políticos entre ese día 10 de octubre y las postrimerías del mes de diciembre. No obstante, la fiscalía del Consejo de Castilla no formalizaría su propuesta de resolución del expediente hasta comienzos de junio de $1788 .{ }^{24}$

Los primeros informes, aparte de escuetos, resultaban alarmantes e imprecisos. La ciudad se encontraba, según su ayuntamiento, «en el más deplorable estado, horror y espanto que jamás se ha visto». Se carecía de noticias ciertas sobre «la multitud de estragos» que las aguas hubieran podido ocasionar «en medio de la confusión y desorden propios de semejantes acontecimientos». Los miembros del cabildo ciudadano manifestaban el celo con que habían puesto en marcha todos los socorros que les había «dictado la humanidad a expensas de los caudales comunes, como lo ha practicado en otras ocasiones de menor peligro y necesidad», y solicitaban al intendente comunicara al Consejo de Castilla este extremo para que diera su aprobación a los recursos gastados. ${ }^{25}$ En este tipo de situaciones las recomendaciones del intendente de turno solían resultar decisivas para la toma de decisiones desde la Corte, sobre todo las relativas a autorización de gastos y dispensa o aplazamiento del pago de contribuciones (Alberola 2019a: 316-323; Alberola 2019b: 72-81; Alberola1999: 151-155 y 176-185). En el caso de Tortosa, sin embargo, correspondería un mayor protagonismo al capitán general y a la Real Audiencia.

22. Ibid.

23. El barón de La Linde a don Juan de Membiela, Barcelona, 13 de octubre de1787, AHN, Consejos, legajo 23587, ff. 7-10

24. AHN, Consejos, legajo 23587, El fiscal del Consejo de Castilla al Relator Celada, Madrid y junio 9 de 1788, ff. $150-152 \mathrm{v}$

25. Véase nota 12. 
El corregidor Diego de Brias, por su parte, hacía notar que a las nueve de la noche del día 8 el ímpetu de las aguas se había llevado el puente de barcas de la ciudad y arrastrado a varios de sus operarios - en esos momentos se hablaba de trece o catorce hombres, tres de ellos fallecidos-, que las calles y arrabales estaban inundados y que sus primeras providencias se habían encaminado a coordinar a todas las autoridades para conseguir embarcaciones — «lanchas»— con las que salvar el mayor número posible de gentes que huían de sus casas por ventanas y balcones. El propio Brias manifestaba que había tenido que abandonar la suya, con su familia, y dirigirse hacia el cuartel de la tropa, en la cuesta de Santa Clara, donde permanecía en compañía de una multitud que contemplaba como se iban desplomando los edificios mientras llegaban noticias alarmantes sobre más derrumbes y muertes. «La ciudad está a punto de perderse», escribía el corregidor al intendente, con tono sombrío, mientras le solicitaba el envío de víveres:

La confusión, horror y espanto de las gentes y la total mira que tengo en precaver el que no se arruinen del todo las muchas casas que estaban cayéndose no me permite por ahora participar a V. S. con individualidad el número de personas que han perecido y demás desgracias que han ocurrido, pero lo executaré luego que lo tenga todo averiguado con lo demás que ocurra. ${ }^{26}$

Y, ciertamente, la información se fue acumulando en los días subsiguientes. El 14 de octubre, el ayuntamiento tortosino —encabezado por su alcalde mayor-dirigía un nuevo informe, algo más preciso, al barón de La Linde en el que ya reseñaba pérdidas en torno a las 1.000 libras por la ruina de algunos de los bienes de propios municipales; concretamente los molinos y la presa del azud..$^{27}$ También daba cuenta de que los restos del puente de barcas se esparcían por las orillas del río y llegaban hasta la playa de Vinaroz, «distante nueve leguas de la ciudad», de que ciento setenta casas se habían derrumbado en el casco urbano y sus arrabales y de que más de doscientas se encontraban apuntaladas y en grave riesgo de hundimiento. No aventuraba cifra alguna de fallecidos, salvo tres mujeres intramuros de la ciudad, y estimaba en más de cuatrocientas las familias que se habían visto obligadas a abandonar sus casas para refugiarse en conventos, colegios, cuarteles y lugares elevados. La necesidad de socorrer a todas ellas y de hacer frente a los gastos provocados «por esta calamidad; y que son innumerables las providencias que exige la naturaleza de este triste acontecimiento», habían dejado vacías, en apenas cuatro días, las arcas municipales.

La remisión de este nuevo escrito al intendente barón de La Linde se cruzó con el envío a Pedro Rodríguez Campomanes, gobernador interino del Consejo de Castilla, de un informe en términos muy similares, aunque con algunas precisiones interesantes. ${ }^{28} \mathrm{El}$ al-

26. Don Diego de Brias al barón de La Linde, Tortosa, 10 de octubre de-1787, AHN, Consejos, legajo 23587, ff. 5-6.

27. El Ayuntamiento de la ciudad de Tortosa al barón de La Linde, Tortosa, 14-10-1787, AHN, Consejos, legajo 23587, ff. $1-2$.

28. El Ayuntamiento de la ciudad al Ilmo. Sr. Conde de Campomanes, Tortosa, 14 de octubre de 1787, AHN, Consejos, legajo 23587, ff. 11-13v. 
calde mayor, Nicolás Campaner y Sastre de la Gineta, manifestaba que la «impetuosa lluvia que parecía segundo diluvio universal» había hecho que el nivel de las aguas alcanzara los 30 palmos en la práctica totalidad del casco urbano - que había quedado dividido en dos por la corriente-, con excepción de dos pequeños promontorios en los que se agolpaban los vecinos. La campiña y huerta ofrecían un «espectáculo digno del mayor dolor», con el arbolado, los campos y las casas destruidos y las tierras dispuestas para la sementera arrasadas. Repetía los daños contabilizados en la ciudad en cuanto a edificios derruidos y apuntalados ,y avanzaba que los muertos en la huerta y arrabales serían muy numerosos, pero que había que esperar «hasta que pasados algunos días nos manifiesten las orillas del Mar y Río y lo interior de las ruinas los infelices que fueron desgraciadas víctimas de tan inopinada y nunca oída inundación del Río Ebro» ${ }^{29}$ Con el fin de "conservar la salud pública», se habilitó un cementerio provisional extramuros de la ciudad para enterrar a todos ellos.

Los edificios que se salvaron de la ruina acogieron a muchos damnificados, al igual que el cuartel de Reales Guardias Españolas y algunos de los inmuebles propiedad de las instituciones religiosas asentadas en la ciudad. El informe estimaba que dos terceras partes de esta quedarían inhabitables «por mucho tiempo», que las monjas de la Concepción se habían visto obligadas a abandonar su convento para trasladarse al de Santa Clara y que el cuartel de San Blas y la antigua Lonja eran pura ruina. Todos los géneros existentes en las tiendas de los comerciantes se habían perdido arrastrados por las aguas, al igual que los granos almacenados por los labradores y los bienes de la práctica totalidad de los vecinos. Por vez primera se alude a los pueblos de la Ribera del Ebro; simplemente para indicar que apenas quedaban casas en pie.

El alcalde mayor, con evidente intención, destacaba que las autoridades «desde la primera hora no nos hemos descuidado en disponer quantos auxilios estimamos oportunos». En efecto: se acudió en socorro de quienes habían quedado aislados en azoteas o árboles, se apuntalaron las casas y se aprontaron abastos «en abundancia y sin alteración de precio». Estas acciones, estrictamente vinculadas a lo «terrenal», tuvieron su contrapunto «espiritual» con el inicio inmediato de rogativas públicas, que se mantendrían hasta la noche del 15 de octubre. A este primer informe destinado a Campomanes siguió otro, cuatro días después, en el que el alcalde mayor reiteraba, «con mayor extensión [...] los violentos estragos causados», e incorporaba «noticias que entonces no pudieron darse». ${ }^{30}$ Aún remitiría el ayuntamiento, en la misma fecha, al gobernador del Consejo de Castilla información muy similar, aunque más sucinta, avalada por sus capitulares y, esta vez sí, por el corregidor Brias. ${ }^{31}$

El primero de estos escritos lo dirigía personalmente el alcalde mayor, Nicolás Campaner, al gobernador del Consejo de Castilla. No era la primera vez que hacía tal cosa en su carrera político-administrativa: en octubre de 1783, y cuando ostentaba la alcaldía mayor

29. Ibid.

30. Don Nicolás Campaner y Sastre de la Gineta al Ilmo. Sr. Conde de Campomanes, Tortosa, 18 de octubre de 1787, AHN, Consejos, legajo 23587, ff. 14-17v.

31. El Ayuntamiento de la ciudad de Tortosa al Ilmo. Sr. Conde de Campomanes, Tortosa, 18 de octubre de 1787, AHN, Consejos, legajo 23587, ff. 18-19v. 
de Orihuela, ya hubo de rendir un detallado informe sobre la tremenda avenida del río Segura que inundó la ciudad y ocasionó un sinnúmero de desgracias. ${ }^{32}$ En el caso que ahora nos ocupa, además de proporcionar datos ya muy contrastados sobre los estragos ocasionados por la crecida del Ebro, Campaner reivindicaba la actitud con que los responsables políticos de la ciudad afrontaron el desastre en medio de enormes dificultades y carencias. De entrada, el alcalde mayor afirmaba que el nivel del Ebro superó en 13 palmos la altura de la «grande avenida» de 1743, «llegando hasta un punto nunca visto ni oído de los nacidos». ${ }^{33}$ Para él, fueron las intensas lluvias - «parecía que todo el cielo se había convertido en agua»-, las causantes de una crecida que, aunque amenazante, «no se esperaba fuese considerable». He aquí una muestra de imprevisión, pues crecida e inundación propiciaron la salida de madre del Barranco del Rastro que dividió en dos partes la ciudad, dejándolas incomunicadas. A esta circunstancia, y a otras muchas, aludiría un impreso posterior - muy crítico- aparecido en 1804 en el que se ponían de manifiesto los numerosos riesgos que hacían de Tortosa una ciudad muy vulnerable a una meteorología adversa; secularmente conocida y padecida (García Zamora 1804).

\section{Combatiendo la catástrofe: un ayuntamiento «en guardia permanente»}

El propio gobierno ciudadano se vio afectado de lleno, pues el corregidor quedó temporalmente aislado y el alcalde mayor, tras constituir en su propia casa un «continuo ayuntamiento» en el que se trabajó noche y día, hubo de tomar decisiones en sintonía con los regidores disponibles. Así, «sin aguardar permiso del Governador, que estaba al otro lado», se priorizó el socorro a los vecinos y, ante la escasez de lanchas, se dispuso la construcción de balsas para recorrer las calles y recoger a quienes pedían auxilio desde pisos altos, azoteas o encaramados a los árboles. Se libró oficio al juez de Marina para que, con embarcaciones, y cuando la corriente lo permitiera, se dirigiera a los arrabales de San José, San Javier y La Cruz para distribuir víveres a unas seiscientas personas. Asimismo, se organizaron cuadrillas de albañiles y peones con el mandato de apuntalar las casas que aún resistían, de romper las paredes que impedían el paso de unos edificios a otros y de retirar cuantos obstáculos impidieran la circulación de las aguas para así restituir las comunicaciones. Otras providencias dictadas perseguían limpiar el barro acumulado, desaguar mediante acequias las aguas embalsadas, enterrar a los ahogados en cementerios provisionales extramuros de la ciudad y hacer lo propio, en hoyos cavados al efecto, con «el inmenso número de reses y caballerías muertas».

El trigo y los granos existentes en los almacenes y en las casas de los labradores, tras quedar sumergidos bajo las aguas putrefactas, se echaron a perder y fueron embargados por el ayuntamiento al considerarlos una seria amenaza para la salud. De los exiguos fon-

32. Don Nicolás Campanery Sastre de la Gineta, alcalde mayor de Oribuela, al conde de Campomanes, Oribuela, 14 de octubre de 1783, AHN, Consejos, legajo 37136.

33. Don Nicolás Campaner y Sastre de la Gineta al Ilmo. Sr. Conde de Campomanes..., f. 14. 
dos de propios de la ciudad se emplearon caudales para comprar pan, vino, carne, arroz, pescado salado y otros víveres. Como quiera que los dominicos aportaron parte de sus reservas de harina, se confiscaron las artesas de los particulares para que las mujeres pudieran amasar con el fin de que «no faltase, como no faltó, pan». El problema consistió en poderlo cocer, pues de los catorce hornos que existían en la ciudad solo quedaron útiles tres según Miravall (1997: 79); aunque la Noticia de lo acaecido en Tortosa aumenta hasta 21 el número de estos establecimientos, de los que solo se salvaron cuatro. ${ }^{34}$

El alcalde mayor tortosino elogiaba asimismo el comportamiento del estamento clerical, pues proporcionó de inmediato cobijo y sustento a gran número de damnificados. Así, por ejemplo, el cabildo catedralicio aportó diariamente, desde el primer momento, tres carneros y seiscientas raciones de pan. El convento de Capuchinos acogió a mil cuatrocientas personas; más de setecientas se instalaron en los colegios dominicos de San Jorge y Santo Domingo y en el de Santiago y San Matías; asimismo, un «número inmenso» hizo lo propio en el convento de San Francisco y en el cuartel de Guardias Españolas. Y hacía constar, precisamente, la solicitud cursada al capitán general de Cataluña para que trasladara a otros cuarteles al batallón allí alojado con el fin de utilizar el edificio para amparar a quienes se hallaban «sin habitación, derramados por los campos y amontonados en los conventos y casas».35

El informe de Campaner no añadía novedades sobre el estado en que quedaron los arrabales y la huerta, aunque daba cuenta de la destrucción de caminos, carreteras y acequias que servían para desaguar enclaves pantanosos. Mediado octubre ya se estimaban unas pérdidas en torno al millón de pesos y un plazo de cincuenta años para que todo se restituyera «a su antiguo estado». Las noticias sobre los pueblos de la Ribera eran malas: apenas quedaban casas en pie en Xerta, Benissanet, Ginestar y Vinebre y el número de muertos y desaparecidos en los dos primeros era «bastante crecido, aunque incierto todavía», temiéndose se produjera un vacío poblacional.

Por esas fechas ya se contabilizaban 73 fallecidos - 3 eran mujeres de la propia Tortosa-, 261 casas arruinadas - entre las que se contaban hornos y fábricas de jabón-y un número indeterminado pero creciente de hogares apuntalados; circunstancias que provocaban la huida de familias enteras y hacían sospechar a Nicolás Campaner que, al igual que en los pueblos de la Ribera, «más de la mitad de la ciudad quedará inhabitable por mucho tiempo».

A su vez, el informe del ayuntamiento que, en paralelo y firmado por el corregidor - en esta ocasión sí- junto con el alcalde mayor y los regidores, se remitió al conde de Campomanes reiteraba, aunque más brevemente, los comentarios del anterior. No añadía novedades al recuento de fallecidos y casa destruidas, incidía en el lamentable estado en que había quedado la huerta e informaba que, desde ese día 18 de octubre, estaba operativo el barco que trasladaba carruajes de una orilla a otra del río. Insistía que el ayuntamiento se había constituido en sesión ininterrumpida desde el mismo día en que comenzó la tragedia en la casa del alcalde mayor y, lógicamente, enfatizaba sobre la dedicación de los responsables políticos:

34. Noticia de lo acontecido en Tortosa con la inundación (...), f. 91.

35. Ibid., f. 18. 
Estamos incesantemente Governador, Alcalde Mayor, Regidores y Diputados trabajando sin perdonar fatiga en alivio del público en quantos ramos conceptuamos conducentes al maior servicio del Rey y bien del común. ${ }^{36}$

En este sentido, los comentarios vienen a coincidir con lo manifestado con anterioridad por el alcalde mayor quien, además de expresar la impotencia sentida por «las cabezas del pueblo» ante la magnitud del desastre, destacaba el comportamiento de todos y cada de uno de ellos. Del gobernador Diego de Brias se hacía notar que había «desempeñado su obligación en quanto le ha permitido su decrépita edad», coincidiendo con la opinión que transmitió dos años atrás el médico Masdevall a Floridablanca. De los regidores, el informe decía que habían hecho «más de lo que han podido»; y para los responsables militares y de Marina solo tenía palabras de elogio por su actitud «promta a los auxilios que se les han pedido», siempre guiados por «la más distinguida humanidad». Respecto de sí mismo, Nicolás Campaner reiteraba que llevaba trabajando sin descanso desde el primer momento y que solo lamentaba no disponer de «mayores fuerzas y caudal para sacrificarlo al mayor servicio del Rey y bien de los pobres». ${ }^{37}$ Comentarios de todo punto lógicos que, en posteriores comunicaciones, serían reiterados y ampliados.

El 23 de octubre, tras informar previamente a Carlos III, Campomanes trasladaría ambas misivas a Juan Antonio Rero y Peñuelas, escribano de Cámara del Consejo de Castilla para los asuntos de Aragón. ${ }^{38}$ Un día después, la sala de gobierno del alto tribunal, se daba por enterada, aprobaba las providencias tomadas por los responsables políticos de Tortosa, agradecía su «celo y actividad», y autorizaba el desembolso efectuado hasta el momento desde los fondos de propios de la ciudad de Tortosa y de otras poblaciones afectadas para auxiliar a los afectados. ${ }^{39}$ Como era habitual en estos casos, recordaba la obligación de llevar puntual registro de los gastos, de reintegrarlos lo más pronto posible a la caja de la que salieron y de comunicar todas estas circunstancias a la Contaduría de la Intendencia de Cataluña.

En consecuencia, se ordenaba al intendente que facilitara los caudales precisos, y al capitán general y presidente de la Audiencia de Cataluña que proporcionara «los auxilios necesarios a reparar las ruinas y desgracias que las avenidas del Río ocasionaron en Tortosa y sus inmediaciones». El acuerdo de la sala de gobierno exigía, además, a la Audiencia que informara de las acciones que, al respecto hubiera emprendido; pues no constaba hubiera hecho nada hasta el momento. ${ }^{40}$ Resulta obvio que este comentario causaría hondo malestar al conde del Asalto, capitán general y presidente del Real Acuerdo en Cataluña.

36. El Ayuntamiento de la ciudad de Tortosa al Ilmo. Sr. Conde de Campomanes..., f. 19.

37. Don Nicolás Campaner y Sastre de la Gineta al Ilmo. Sr. Conde de Campomanes..., f. 14v y 18v.

38. El conde de Campomanes a don Juan Antonio Rero y Peñuelas, Madrid, 23 de octubre de 1787, AHN, Consejos, legajo 23587, ff. 20-20v.

39. Certificaciones de la sala de gobierno, Madrid y octubre veinte y cuatro de 1787, AHN, Consejos, legajo 23587, ff. 21-22.

40. Ibid., ff .21v-22. 


\section{El protagonismo de la Capitanía General y el Real Acuerdo en el seguimiento del desastre}

La resolución del Consejo de Castilla fue remitida mediante real orden, fechada el 24 de octubre, al gobernador, ayuntamiento y alcalde mayor de Tortosa haciendo constar que se enviaban copias, a la vez, al intendente y al presidente de la Audiencia. ${ }^{41} \mathrm{El}$ primero de estos acusó recibo el día 30 de manera escueta y conforme a las normas; comprometiéndose a facilitar los auxilios necesarios a Tortosa y al resto de las poblaciones afectadas por la riada e inundación. ${ }^{42}$ La respuesta del capitán general, en su calidad de presidente de la Audiencia, discurrió por otros derroteros menos formalistas, sin ocultar su desagrado por la indisimulada reconvención que la orden del Consejo de Castilla le propinaba por su aparente inacción.

A finales de octubre el capitán general hacía patente a Juan Antonio Rero su malestar por la pretendida inasistencia a los damnificados que el Consejo de Castilla atribuía a la Capitanía General y a la Audiencia barcelonesas. ${ }^{43}$ En su condición de máxima autoridad militar el conde del Asalto presidía el Real Acuerdo, organismo que reunía el pleno de la audiencia en torno suyo para discutir asuntos gubernativos. Es bien conocida la falta de sintonía que existió entre los poderes militar y civil, encarnado este último por los magistrados de aquella, y que se plasmó en los frecuentes «desacuerdos» que mantuvieron (Escartín 1984: 117-118; Pérez Samper 1996; Andújar 2004; Giménez 2004).

Francisco Fermín González de Bassecourt, primer conde del Asalto, ejerció como capitán general de Cataluña entre 1778 y 1789; hasta 1780 en calidad de interino. Durante su mandato llevó a cabo obras de mejora urbanística en la ciudad de Barcelona y desempeñó, desde 1776 y hasta su muerte, la presidencia de la Real Academia de Buenas Letras. Hay cierto consenso en considerar que se condujo con talante «ilustrado» y llevó a cabo importantes reformas en el callejero urbano; pero su deficiente gestión de los graves alborotos conocidos como rebomboris del pa, acaecidos en Barcelona y otras ciudades entre febrero y marzo de 1789, provocó su destitución y traslado a Madrid (Mercader 1957: 108-110; Castells 1970: 5-81).

En lo tocante a los asuntos de Tortosa, y para deshacer malentendidos, el conde del Asalto escribió al secretario de la Cámara del Consejo de Castilla comunicándole que, como responsable del poder militar en Cataluña y con funciones «informativas» de todo orden (Andújar 2004: 311-312), tuvo conocimiento de la inundación de la ciudad a través de sendas cartas fechadas en 9 y 10 de octubre remitidas por el ayuntamiento tortosino. Además, el alcance del suceso se lo confirmó, igualmente, el comandante del Batallón de Guardias

41. AHN, Consejos, legajo 23587, ff. 22-28v. Figuran los escritos de remisión, con fecha 24 de octubre de 1787, de todas las providencias del Consejo de Castilla; certificadas dirigidas al Ayuntamiento de Tortosa, al barón de La linde -intendente de Cataluña - y al conde del Asalto - capitán general y presidente de la Audiencia de Cataluña.

42. El barón de La Linde a don Juan Antonio Rero y Peñuelas, Barcelona, 30 de octubre de 1787, AHN, Consejos, legajo 23587 , f. 31.

43. El conde del Asalto a Don Juan Antonio Rero y Peñuelas, Barcelona, 31 de octubre de 1787, AHN, Consejos, legajo 23587 , ff. 32-33. 
Españolas. Ante la demanda de ayuda, dispuso el envío de víveres y encargó al gobernador de Tarragona que previniese a los pueblos de su demarcación para que también contribuyeran. Y si no hizo más en esos momentos, aducía, fue porque el ayuntamiento le avisó el día 14 del descenso del nivel de las aguas del Ebro y la disponibilidad de comestibles «en abundancia y sin alteración de precios». Recordó, asimismo, que, a instancias de la ciudad, trasladó a Reus el batallón de Guardias Españolas para que su cuartel acogiera sin estrecheces a las víctimas de la inundación; cosa que ya venía haciéndose desde los primeros momentos «con indecible cariño de parte de esta [tropa] y sus oficiales».

Insistía que, de todo ello, había informado al conde de Floridablanca y remitido copia al Consejo. No obstante, hacía notar que los oficios que recibía del ayuntamiento resultaban imprecisos y muy generales, «sin incorporar pormenor, tal y como corresponde para tomar juicio [...], y de las desgracias sucedidas en la Ribera del Ebro se hablaba con mucha variedad». Apuntaba, no exento de razón, que esta era la forma habitual de conducirse de las poblaciones afectadas por alguna desgracia cuando elevaban súplicas y peticiones:

Es la regla que comúnmente siguen los que escriben de asuntos de esta naturaleza; por lo que, como que les conozco, exijo siempre de ellos la correspondiente especificación [...y por ello]; mandé al Gobernador de Tortosa en carta de 20 que, desde luego, mandase a inquirirlas ciertas al Ayudante de la Plaza D. Luis de la Cuesta, que es inteligente, activo y celoso, y me diese cuanta con relación firmada. ${ }^{44}$

Concluía el conde del Asalto indicando que si aún no había dado traslado de estos datos era porque ni el ayuntamiento ni el ayudante de la plaza se los habían proporcionado. Y hasta ahí alcanzaba su gestión desplegada como capitán general. Como presidente de la Audiencia no había hecho cosa alguna porque, aducía, nadie se había dirigido al alto tribunal en demanda de nada; cosa a todas luces cierta y, probablemente, poco reprochable desde el punto de vista del procedimiento administrativo pero que, no obstante, podría denotar un evidente desinterés, por su parte, en que la capacidad gubernativa propia de la Audiencia en su vertiente «civil» - los magistrados- pudiera actuar.

En cualquier caso, y tras la reconvención del Consejo de Castilla, convocó el Real Acuerdo para dar cuenta a sus miembros de «la primera noticia de oficio que ha tenido esta Vuestra Audiencia de los estragos causados en la ciudad de Tortosa y sus campos por la avenida extraordinaria del Ebro»; noticia que, decía, le proporcionaba el alto tribunal el día 24 de octubre mediante real orden que obligaba al órgano judicial y gubernativo de Cataluña a tomar las providencias necesarias para ayudar a las poblaciones afectadas. ${ }^{45}$

A partir de ahí la Audiencia, constituida en Real Acuerdo, emitió un informe en términos muy similares a los de la carta del capitán general. Insistía en que el corregidor y Ayuntamiento de Tortosa no habían dado cuenta del suceso al alto tribunal y que el alcalde mayor «en carta de 23 del que sigue, y en carta que acaba de recibir, disculpándose con sus

44. Ibid.

45. Informe que haze la Real Audiencia en cumplimiento de lo mandado en la orden del Consejo (...), Barcelona, 31 de octubre de 1787, AHN, Consejos, legajo 23587, ff. 34-36v. 
graves ocupaciones escribe alguna noticia después ya pasada la principal urgencia». ${ }^{46}$ Se reconocía, no obstante, que el ayuntamiento había escrito los días 10, 13 y 14 de octubre al capitán general «refiriendo las tristes circunstancias de aquella población y de sus vecinos»; pero sin explicitar en ningún momento que se hacía "para inteligencia de la Audiencia» lo que había inclinado a pensar al capitán general que «el tribunal tendría iguales noticias», tal y como había sucedido con el intendente. Obviaba el conde del Asalto que en su persona confluían dos cargos, uno netamente militar y de carácter unipersonal y otro colegiado, integrado por magistrados a quienes presidía y con competencias de carácter gubernativo en las que el talante político y civilista resultaba esencial; aunque a él, y a todos los que ocuparon Capitanías Generales durante el siglo xviI, les resultara incómodo.

La Audiencia, que no había «providenciado hasta ahora cosa alguna en el asunto», comunicó que en cumplimiento de la real orden cursada por el Consejo de Castilla emplearía «todas sus miras a fin de proporcionar a la ciudad de Tortosa y sus vecinos los alivios que exige su triste situación en tan grave desgracia». Y así haría en lo sucesivo, cobrando un gran protagonismo. Todo ello sin dejar pasar la ocasión de reprender al corregidor y ayuntamiento tortosinos por la «omisión que han tenido en este caso, a fin de que no se padezca en lo sucesivo». ${ }^{47}$ Tanto el escrito del capitán general como el informe del Real Acuerdo tuvieron entrada en la secretaría del Consejo de Castilla el 10 de noviembre y, de inmediato, llegaron al fiscal. A partir de ese momento, la Audiencia pasaría a desempeñar un mucho activo papel en el asunto; mayor incluso que el de la propia Intendencia, habitual instancia responsable del seguimiento directo de este tipo de sucesos.

\section{El coste y financiación de los socorros y de la reconstrucción}

En las postrimerías del mes de octubre se podría decir que la información, pese a algún que otro roce institucional, había fluido con agilidad y las diferentes instituciones se habían podido formar una idea cabal del alcance de la catástrofe. No obstante, seguían llegando a la mesa del intendente peticiones de algunas poblaciones afectadas, caso de Gandesa, ${ }^{48}$ así como valoraciones más detalladas que de la afectación de ciertos bienes de propios de la ciudad de Tortosa habían llevado a cabo peritos expertos.

En el primer caso, la villa solicitaba el 27 de octubre al intendente barón de la Linde autorización para detraer de sus fondos de propios las cantidades necesarias para reconstruir de inmediato su molino harinero y la acequia aneja que la riada del Ebro había destruido. Su importe, según estimación de experto ascendía a más de 1.000 libras, a las que se debían añadir otras 300 que importó la construcción de un dique en la última noche de avenida para impedir que las aguas inundaran la población. Avalaba la petición del ayuntamiento una nota manuscrita por el cura párroco de la villa en el margen de la última hoja

46. Ibíd., f. $34 \mathrm{v}$.

47. Ibíd. ff. 35-35v.

48. La villa de Gandesa al barón de La Linde, Gandesa, 27 de octubre de 1787, AHN, Consejos, legajo 23587, ff. 38-40v. 
del documento. ${ }^{49}$ Con fecha de 3 de noviembre, el intendente autorizaba el gasto y daba cuenta de ello al secretario de la Cámara del Consejo de Castilla.

En el caso de Tortosa, el ayuntamiento, además de informar de los avances en la reparación del puente de barcas, de caminos y carreteras,${ }^{50}$ trasladaba al intendente que el presupuesto para la reparación del azud, casa de la pesquera y de varios molinos harineros, con sus instalaciones anejas, todos ellos pertenecientes a los propios de la ciudad, ascendía a 12.650 (cuadro 1). ${ }^{51}$ Como quiera que los ingresos anuales que reportaban superaban en cada ejercicio económico las 4.000 libras se solicitaba del barón de La Linde la máxima urgencia en su decisión; petición que fue atendida. ${ }^{52}$

\section{Cuadro 3 \\ Evaluación de los daños en algunos bienes de Propios de la ciudad de Tortosa (31 de octubre de 1787)}

\begin{tabular}{|l|l|l|l|}
\hline $\begin{array}{l}\text { TIPO DE } \\
\text { PROPIO }\end{array}$ & LOCALIZACIÓN & DESCRIPCIÓN DE DAÑOS & $\begin{array}{l}\text { VALORACIÓN } \\
\text { DE DAÑOS } \\
\text { (en libras) }\end{array}$ \\
\hline Molino & $\begin{array}{l}\text { «de la parte de la villa } \\
\text { de Xerta» }\end{array}$ & $\begin{array}{l}\text { Tejado hundido, paredes derrumbadas. } \\
\text { Casa del molinero destruida } \\
\text { Arrastradas 7 muelas y los aros; puerta } \\
\text { del establo arrastrada por las aguas } \\
\text { Dos puertas arruinadas } \\
\text { Cups, balsas y acequias llenas de tierra } \\
\text { y basura }\end{array}$ & 2.000 \\
\hline $\begin{array}{l}\text { Casa de la } \\
\text { pesquera }\end{array}$ & - & $\begin{array}{l}\text { Horno demolido, paredes desplomadas, } \\
\text { rotura de la escalera, bovedillas y } \\
\text { tabiques; terrado hundido } \\
\text { Granero: derrumbe de paredes y rotura } \\
\text { del terrado }\end{array}$ & 200 \\
\hline $\begin{array}{l}\text { Salador de } \\
\text { la pesquera }\end{array}$ & - & Rotura parcial de paredes y tejado & 100 \\
\hline
\end{tabular}

49. Este tipo de anotación, e incluso informes largos, se suele encontrar en los expedientes iniciados por poblaciones de pequeña y mediana entidad. En este caso, el presbítero Juan Martínez señalaba textualmente: «Cuanto narra esta carta del Ayuntamiento es la pura verdad i considero el asunto digno de la piedad de V. S.», Ibíd., f. 39v. Véase al respecto Alberola (2009).

50. El Ayuntamiento de la ciudad de Tortosa al barón de La Linde, Tortosa, 31 de octubre de 1787, AHN, Consejos, legajo 23587, ff. 43-44.

51. Informe de los comisionados por el Muy Ilustre Ayuntamiento de esta ciudad para pasar al reconocimiento de la asut, molinos y casas, y hacer relación de las ruinas ocasionadas con la avenida del Ebro, AHN, Consejos, legajo 23587 , ff. $42-42 \mathrm{v}$.

52. El barón de La Linde a don Juan Antonio Rero y Peñuelas, Barcelona, 3 de noviembre de 1787, AHN, Consejos, legajo 23587, ff. 45-45v. 


\begin{tabular}{|l|l|l|r|}
\hline Molino & «de la parte de & $\begin{array}{l}\text { Tejado hundido } \\
\text { Tivenys» }\end{array}$ & $\begin{array}{l}350 \\
\text { Paredes derrumbadas a la altura de la } \\
\text { muela } \\
\text { Muela volandera arrastrada } \\
\text { Cup lleno de tierra y basura } \\
\text { Casa del molinero: paredes y tabiques } \\
\text { rotos, pérdida de tejas y ladrillos del } \\
\text { terrado }\end{array}$ \\
\hline Azud & - & $\begin{array}{l}\text { Cubierto por las aguas: difícil de evaluar } \\
\text { los daños } \\
\text { Aparenta gran ruina } \\
\text { Arrastre de la piedra preparada para su } \\
\text { reparación }\end{array}$ & \\
\hline TOTAL & - & - & 10.000 \\
\hline
\end{tabular}

Fuentes: Informe de peritos [...], AHN, Consejos, legajo 23587, ff. 92-92v. y elaboración propia.

Cuestión de enorme interés y no menor trascendencia —nada conocida, por ciertofue la desaparición de una importante cantidad del papel sellado que se custodiaba en un armario de las casas capitulares. El ayuntamiento se apresuró a comunicarlo el día 3 de noviembre al intendente, habida cuenta que la riada se había llevado 112 pliegos del sello primero, 560 del segundo, 441 del tercero, 2.748 del cuarto y 662 del de oficio..$^{53}$ La preocupación de los regidores de la ciudad estaba justificada; bástese recordar la importancia y obligatoriedad del uso del papel sellado para cualquier trámite administrativo desde que fuera establecido durante el reinado de Felipe IV (Baltar 1996: 519-560). No se trataba únicamente de las pérdidas económicas que pudieran representar todas las resmas desaparecidas; la cuestión principal radicaba en si restaba suficiente papel para poder seguir tramitando expedientes. El intendente solicitó la justificación de la cantidad en metálico que representaba todo ese papel sellado, con el fin de darlo de baja en su contabilidad total, aunque advertía que ello no entraba dentro de sus competencias y que debía comunicarlo a «la superioridad». Entretanto, recomendaba al ayuntamiento hiciese gestiones ante el marqués de la Corona, superintendente general del ramo (Moxó 1959: 609-668) o, mejor aún, al propio secretario de Hacienda, Pedro de Lerena. ${ }^{54}$

En cualquier caso, trasladaba la consulta al Consejo de Castilla y solicitaba instrucciones al respecto. El 20 de noviembre, el escribano de Cámara para los asuntos de Aragón le transmitía el acuerdo del alto tribunal por el que ordenaba a los capitulares de Tortosa que acudieran a la vía reservada de la secretaría de Hacienda para resolver el asunto..$^{55}$ Desconocemos cuál fue el resultado.

53. El barón de La Linde al Ayuntamiento de Tortosa, Barcelona, 9 de noviembre de 1787, AHN, Consejos, legajo 37156 , s. f.

54. AHN, Ibid., s. f.

55. El barón de la Linde a D. Juan Antonio Rero y Peñuelas, Barcelona, 30 de noviembre de 1787, AHN, Ibíd., s.f. 


\section{Enterados en la corte: la Relación de lo acontecido en la ciudad de Tortosa con la ynundación del río Ebro y la solicitud de ayudas para superar la catástrofe}

El documento oficial elaborado por el ayuntamiento en el que se recogían los pormenores del suceso estuvo listo a finales del mes de octubre. Denominado Relación de lo acontecido en la ciudad de Tortosa con la inundación del Río Ebro que empezó el día 8 de octubre de este corriente año 1787, constituía la base para conocer el grado de afectación del territorio, bienes y personas. También había de servir de instrumento para establecer prioridades a la hora de la reconstrucción y distribución de ayudas. Se puede decir que su remisión a diferentes instancias y personalidades estuvo bien planificada y el día 14 de noviembre el Ayuntamiento de Tortosa expidió, de manera simultánea, misivas al rey Carlos III, al conde de Floridablanca, al intendente y al capitán general y presidente de la Audiencia de Cataluña. A todas ellas acompañaba una copia de la Relación. Cuatro días más tarde partía hacia la Corte una última dirigida al conde de Campomanes. ${ }^{56}$

La que recibió Carlos III, ${ }^{57}$ figuraba anexa a una larga súplica en la que, en tono dramático, el corregidor y los miembros del cabildo ciudadano tortosino exponían la «infeliz situación» en que había quedado la ciudad y sus habitantes, «quasi todos en el más deplorable estado» con todos sus bienes «sepultados en las corrientes o inutilizados en las ruinas de las casas». Además de reiterar información ya conocida, incluía algunas precisiones. Por ejemplo, hacía notar lo mucho que habían padecido «los pueblos de Benifallet, Tivenys, Cherta y Aldover», los cuales eran «aldeas de la ciudad» y sus habitantes se «reputaban vecinos» de Tortosa, por lo que «su beneficio» interesaba mucho a esta. ${ }^{58}$

El conde de Floridablanca, primer secretario de Estado, recibió igualmente la carta del ayuntamiento con la súplica y Relación dirigidas al rey acompañadas de un memorial del gremio de labradores de Tortosa. ${ }^{59}$ Todo ello lo envió aquel el 8 de diciembre a Campomanes para que el Consejo de Castilla actuara en consecuencia. ${ }^{60}$ Tres días después la sala de gobierno del Consejo se daba por enterada.

Cuando las consabidas carta y Relación llegaron a manos del intendente de Cataluña, apenas tardó tres días en despachar el original de esta última al Consejo de Castilla, aunque no llegó a dejar un duplicado en su oficina. De ahí que suplicara «que de la expresada Relación que remito al Consejo me dirija una copia para que pueda tenerse siempre

56. El Ayuntamiento de Tortosa al Imo. Sr conde de Campomanes, Tortosa, 18 de noviembre de 1787, AHN, Consejos, legajo 23587, ff. 73-85v.

57. El Ayuntamiento de Tortosa a Carlos III, Tortosa, 14 de noviembre de 1787, AHN, Consejos, legajo 23587, ff. $110-112$.

58. Ibid., ff. 98-109.

59. El Ayuntamiento de Tortosa al Exmo. Sr. Conde de Floridablanca, Tortosa, 14 de noviembre de 1787, AHN, Consejos, legajo 23587, ff. 112-112v. Igualmente, Memorial de los mayordomos electos y concejales del Gremio de Labradores de san Antonio Abad de la ciudad de Tortosa, 11 de noviembre de 1787, AHN, Ibíd., ff. 113-114.

60. El conde de Floridablanca al sr. Conde de Campomanes, Madrid, 8 de diciembre de 1787, AHN, Consejos, legajo 23587, ff. 116-116v. 
presente en esta Yntendencia, respecto de que no ha permitido el tiempo sacarla aquí antes de su remisión». ${ }^{61}$

Por su parte, el conde del Asalto, capitán general y presidente del Real Acuerdo, tras examinar los documentos reenvió al conde de Campomanes el día 28 del mismo mes la Relación, no sin antes reelaborarla y modificar su nombre por el de Noticia. No variaba su contenido en lo sustancial, pero, como ya se ha comentado, incorporaba una comparación del impacto de esta inundación con el de otras anteriores de similar gravedad. ${ }^{62}$ Acompañaban a la Noticia otros documentos interesantes; entre ellos el informe, elaborado a instancias del capitán general, del ayudante mayor de la plaza, Luis de la Cuesta, que recogía la valoración de la catástrofe en los pueblos de la Ribera y, tras minucioso desglose, estimaba las pérdidas en 1.243 .725 libras y 1 sueldo. ${ }^{63}$ También figuraba otra evaluación de daños correspondiente a Vinebre, llevada a cabo por su baile y remitida por Gaspar Bracho Bustamante, gobernador de Tarragona. Uno y otra tuvieron entrada en el Consejo de Castilla el día 7 de diciembre de $1787 .{ }^{64}$

Con todo ello, se puede decir que los trámites de recepción de información del suceso y de solicitud de ayudas quedaban completos en apenas dos meses de sucedida la desgracia. Tocaba establecer, además del modo de compensar a los vecinos de las pérdidas ocasionadas por el desastre, la dotación y procedencia de los fondos que habrían de cubrir las cuantiosas cantidades que el Ayuntamiento de Tortosa había empleado para socorrer a la población desde los primeros momentos, así como para afrontar las constantes exigencias de toda índole que, día tras día, deparó la inundación.

Para lo primero hacía falta la resolución del Consejo; y esta -se sabía— no había de ser inmediata. A finales de diciembre aún andaba este solicitando a la Real Audiencia una propuesta sobre los «arbitrios» a tomar «para el auxilio y alivio» de los vecinos de Tortosa y otras poblaciones. Para lo segundo se escuchó el parecer del ayuntamiento el cual, desde comienzos de noviembre había manifestado al intendente la imposibilidad de recaudar las cantidades establecidas en el Catastro de ese año y, menos aún, de financiar con cargo a los fondos de propios de la ciudad todos los gastos contraídos. ${ }^{65}$ El intendente se había mostrado partidario de suspender el cobro de los impuestos, así como de estudiar alguna propuesta de la ciudad para hacer frente a lo segundo. ${ }^{66}$ Esta no se hizo esperar y el 14 de

61. El barón de La Linde a Dn. Juan Antonio Rero y Peñuelas, Barcelona, 17 de noviembre de 1787, AHN, Consejos, legajo 23587, f. $70 \mathrm{v}$.

62. Noticia de lo acaecido en Tortosa con la inundación del Ebro que empezó el 8 de octubre, AHN Consejos, legajo 23587 , ff. $87-93$

63. Estado que manifiesta los daños que han padecido los pueblos del corregimiento de Tortosa situados sobre la Ribera de Ebro de resulta de la crecida del río en la noche del día 8 de octubre anterior, visto y reconocido por D. Luis de la Cuesta en virtud de orden del capitán general del Principado, tasado todo a juicio prudente de Peritos con asistencia de la Justicia en sus respectivos pueblos, AHN, Consejos, legajo 23587, ff. 87-93.

64. Ibid., ff. 94-96.

65. Cartas del Ayuntamiento de Tortosa al barón de La Linde fechadas en 3 y 7 de noviembre de 1787, AHN, Consejos, legajo 23587, ff. 47-53v

66. El barón de La Linde a D. Juan Antonio Rero y Peñuelas, Barcelona, 10 de noviembre de 1787, AHN, legajo 23587, ff. $54-54 \mathrm{v}$ 
noviembre Tortosa planteaba al intendente que, con «sus Propios destruidos», no se le ocurría otra cosa que recurrir al fondo de Expolios y Vacantes correspondientes a la mitra de Tortosa que, según datos del subcolector, suponían más de 20.000 libras. A ellas se añadía una cantidad similar existente en la subcolección de Zaragoza tras la defunción, en esta ciudad, de Pedro Cortés Larraz, último obispo de Tortosa. ${ }^{67}$ Este prelado ocupó la sede entre el 4 de febrero de 1780 y finales de 1786 en que renunció al obispado y se retiró a Zaragoza, donde fallecería el 7 de julio de 1787. Su sucesor fue Victoriano López Gonzalo quien pasó de la diócesis de Tlaxcala-Puebla (México), con sede en Puebla de los Ángeles, a la de Tortosa en octubre de 1787 coincidiendo con la avenida del Ebro e inundación de Tortosa; excelente ocasión para que, como escribió Joaquín Lorenzo Villanueva en su Viage por las iglesias de España, manifestara «su zelo y caridad con su nueva esposa» (1806 IV: 117-118). Así lo hizo don Victoriano que ya acumulaba experiencia en este tipo de situaciones pues en su anterior destino mexicano hubo de hacer frente, junto con el resto de los prelados del México central, al conocido como «Año del hambre» (1785-1786), y adoptar medidas para para socorrer a sus feligreses (Florescano 1981 I: 155-157 y II: 158, 159, 162; Alberola y García Acosta 2021: 27-30).

El 5 de diciembre, en un largo y argumentado informe, la ciudad suplicaba «de la bondad del rey», la concesión de tres «socorros para su restauración». ${ }^{68}$ En primer lugar, el aplazamiento durante ocho años de «reales tributos»; en este caso, las cantidades establecidas anualmente en el Catastro. Alegaba la total destrucción de la economía y la miseria en la que se encontraban labradores, artesanos de todo tipo, comerciantes, marineros, trajineros y vecinos en general tras la pérdida de sus bienes y medios de producción. Hacía ver, además, la imposibilidad material de que el propio ayuntamiento pudiera cobrar las contribuciones y la certeza de que, en caso de hacerlo, su «recaudación produciría un manantial de deudas inextinguibles» entre los contribuyentes. Pero rebajaba un tanto sus pretensiones: si no podían ser ocho años, rogaba que la exención lo fuera «por todo el tiempo que sea de su Real Agrado».

En segundo lugar, solicitaba la creación de un «fondo con destino a socorrer las indigencias» con el que poder hacer frente a los incontables gastos contraídos y a los que quedaban por llegar para alcanzar la recuperación de todo lo perdido. Indicaba, como se acaba de anotar, la existencia tanto en Tortosa como en Zaragoza, de caudales pertenecientes a los Expolios y vacantes de la mitra tortosina que, convertidos en limosnas, servirían para aliviar la lamentable situación de los vecinos sin necesidad de suspender tributos municipales que, a fin de cuentas, venían a nutrir los fondos de Propios y arbitrios del municipio. Se estimaba en unas 40.000 libras el monto de esos expolios. En otras ocasiones, ya se había recurrido a este tipo de recursos como sucedió, por ejemplo, en 1783 con los Expolios y vacantes de las diócesis de la Seu d'Urgell y de Zaragoza para socorrer a los pueblos de

67. El Ayuntamiento de Tortosa al barón de La Linde, Tortosa, 14 de noviembre de 1787, AHN, Consejos, legajo 23587 , ff. $68-69 \mathrm{v}$.

68. El Ayuntamiento de Tortosa al Consejo de Castilla (copia), Tortosa, 5 de diciembre de 1787, AHN, Consejos, legajo 23587, ff. 137-143. 
varios corregimientos aragoneses y catalanes tras perder, reiteradamente, sus cosechas (Alberola y Box 2014: 852-854).

En última instancia, el ayuntamiento pedía permiso al rey para construir casas extramuros de la ciudad. Aducía que en el interior de las murallas todo estaba derruido, que el suelo era inestable y que apenas quedaban solares donde edificar. Argüía, no obstante, que junto a la puerta de San Juan se hallaba uno que, tras haberse librado de la inundación, reunía los requisitos para reubicar a la población. Para justificar la petición invocaba un informe de Luis Marquiegui, ingeniero de la plaza, en el que advertía de la «flojedad del terreno» en el casco urbano, de la necesidad de tomar las mayores precauciones en las tareas de reconstrucción y de lo recomendable que sería nombrar un maestro alarife, «íntegro e inteligente», para examinar y aprobar las excavaciones antes de llevar a cabo labores de cimentación. El documento se extendía en una serie de pormenores muy interesantes en lo que a medidas de seguridad y prevención se refiere; aunque el ayuntamiento advirtió de que, pese a sus deseos, no podía contratar personal por carecer de recursos para ello y solicitó al Real Acuerdo que estudiara el asunto ${ }^{69}$ Esta información tuvo entrada en el Consejo de Castilla el 15 de diciembre y pasó, de inmediato, al fiscal. Cinco días más tarde, una nueva orden dirigida desde el Consejo a la Real Audiencia reclamaba más información sobre los «medios o arbitrios» a tomar para auxilio de los tortosinos. El 29 de diciembre, una minuta del Consejo de Castilla confirmaba que el Capitán General de Cataluña se daba por enterado y que procedería en consecuencia. ${ }^{70}$

Hasta finales de febrero de 1788 no hay más noticias; pero la Real Audiencia debió reclamar detalles precisos sobre el estado de la ciudad, pues el 20 de ese mes el ayuntamiento remitía un nuevo informe al Capitán General en el que resumía los avances experimentados en la gestión del desastre desde el envío de la Relación. Respecto al estado de calles y plazas se indica que las «principales» estaban enteramente transitables, abiertas «para el tráfico y comercio» y libres ya de ruinas y escombros. Los edificios que habían resistido estaban sólidamente apuntalados y la reconstrucción de las casas marchaba a buen ritmo, extremándose la vigilancia de expertos para que la cimentación fuera profunda y sólida. Para ello se habían acopiado materiales «de calidad y en abundancia» a precios «equitativos».

El cruce de una orilla a otra del Ebro ya se llevaba a cabo mediante dos barcos grandes «provisionales» y un número indeterminado de pequeños en servicio constante, estando prevista la entrada en funcionamiento del nuevo puente de barcas para el día 23 de ese mismo mes de febrero. De los caminos públicos y carreteras se decía que se hallaban «rehabilitados» y en el mejor estado que permitían «las actuales circunstancias»; no dejando de insistir en lo exhaustas que se encontraban las arcas municipales tras haber intentado «aliviar» a todos los vecinos. En este sentido alertaba de que el año agrario se preveía malo, temiendo los campesinos perder de nuevo la sementera, tras haberse endeudado con la compra de granos.

69. El Ayuntamiento de Tortosa al Real Acuerdo, Tortosa, 18 de diciembre de 1787, AHN, Consejos, legajo 23587, ff. $132-133 \mathrm{v}$.

70. El conde del Asalto a D. Juan Antonio Rero y Peñuelas, Barcelona, 29 de diciembre de 1787, AHN, Consejos, legajo 23587, ff. 49-49v. 
En última instancia, el ayuntamiento solicitaba la intercesión del capitán general para que la «Real Piedad» concediera las gracias ya demandadas; especialmente la exención de tributos por unos cuantos años. Aunque, por si acaso, ya había elevado una petición similar a la secretaría de Hacienda. ${ }^{71}$

\section{Entre la Resolución Real de 17 de marzo de 1788 y el dictamen de la fiscalía del Consejo de Castilla de junio de ese mismo año: comentarios necesarios}

Llegados a este punto se observan ciertas disfunciones cronológicas en lo que a las tomas de decisión y publicación de disposiciones reales se refiere. Así, una Real Resolución comunicada al Ilustrísimo Obispo de Tortosa con fecha 17 de marzo de 1788, ${ }^{72}$ en respuesta a una petición de este fechada en 16 de febrero, parece sustanciar el asunto que, por otro lado, seguía su trámite en el Consejo de Castilla y que, de hecho, no dictaminó el fiscal hasta el 9 de junio de ese mismo año. Precisamente en términos casi idénticos a la real orden de tres meses atrás. Ello obliga a plantear ciertas cuestiones de no poca relevancia que, por ahora, quedarán sin respuesta. Entre ellas, ¿se emitió una real orden sin esperar a tener toda la información; sobre todo la más «sensible» relativa a la procedencia de los recursos para los socorros? ¿Era posible un pronunciamiento explícito sin considerar las últimas opiniones —en este caso, y como se verá, favorables- del capitán general de Cataluña? Pero, sobre todo, ise podía ignorar el parecer del Consejo de Castilla, encarnado en su fiscal?

Del tenor textual de la Real Resolución se desprende que esta estuvo motivada por el informe que se dirigió al monarca el 16 de febrero; sin embargo, el contenido al que se alude -y sobre el que se fundamenta la resolución- ya era conocido desde el 29 de diciembre de 1787 y, con algo más de detalle, desde el 20 de febrero de 1788. En cualquier caso, la resolución otorgaba la exención del Catastro por cuatro años a Tortosa y a las poblaciones afectadas del curso bajo del Ebro demandada por la ciudad. ${ }^{73}$ No obstante, cabe destacar un detalle importante: aunque la gracia era «absoluta en común» no resultaba de aplicación para aquellos vecinos que estuvieran en condiciones de hacer frente al pago del impuesto. La intención era que con lo que estos aportaran se pudiera socorrer a quienes lo habían perdido todo. De igual modo, se atendía otra de las peticiones del ayuntamiento tortosino al constituirse, por tiempo de cuatro años, un fondo de socorro que había de nutrirse de los caudales procedentes de los Expolios y Vacantes de la mitra de Tortosa. Las infructuosas gestiones hechas en el ya lejano 3 de noviembre del año anterior

71. El Ayuntamiento de Tortosa al Capitán General y Real Acuerdo, Tortosa, 20 de febrero de 1788, AHN, Consejos, legajo 23587, ff. 144-145.

72. Transcrita y comentada por Sabaté y Nulla, (1988 I: 573-580), pero de la que no indican su localización ni procedencia.

73. Se aludía a «Amposta, Aldover, Cherta, Tivenys, Benifallet, Ginestar, Miravet, Benissanet, Mora de Ebro, Ascó, Flix y Ribaroja», Ibid., p. 573. 
por el ayuntamiento ante el Colector General de esos recursos, Pedro Joaquín Murcia, quedaban allanadas con esta disposición real. ${ }^{74}$

Para el manejo y distribución de estos recursos, la Real Resolución contemplaba la creación de una Junta de Socorro integrada por el obispo, el gobernador-corregidor, un regidor nombrado por el ayuntamiento, una dignidad y un canónigo propuestos por el obispo y el cabildo catedral, un Superior de las Órdenes religiosas establecidas en la ciudad elegido por el obispo, dos caballeros, un labrador y un artesano escogidos por el obispo y el gobernador-corregidor. Las sesiones habrían de celebrarse en la residencia del obispo y se establecía el orden en que habían de sentarse los asistentes; una disposición claramente jerárquica acorde con la realidad social de la época y la composición de este órgano. Como secretario sería nombrado Mariano García Zamora quien, años más tarde, llegaría a ser arcediano de la catedral de Tortosa y publicaría un interesante opúsculo en el que se refería a la inundación, manifestaba los riesgos que amenazaban a la ciudad en caso de avenidas y proponía interesantes y bien fundamentadas medidas de prevención y protección (García Zamora 1803).

Es, precisamente, Mariano García Zamora quien figura al pie de la real orden como autor de la copia dando fe de su validez. Ignoro la razón. Catedrático de Teología en el Colegio de San Fulgencio de Murcia, residía en Madrid desde el 4 de abril de 1784 intentando opositar a una cátedra en los Reales Estudios de San Isidro. En un momento determinado, y cuando el expediente estaba a punto de resolverse, el gobernador del obispado en sede vacante, le ordenó restituirse a su cátedra (Mas 1988: 163 y 167-168). También figuraba como miembro de mérito en la Sociedad Económica Matritense, a la que había presentado diferentes memorias. ${ }^{75}$ Los autores de la trascripción y estudio de la real orden lo identifican como «representante del rey» (Sabaté y Nulla 1988 I: 579); sin embargo, ello resulta difícil de «encajar» cronológicamente puesto que, por esas fechas, ni siquiera se había creado la Junta de Socorro de la que había de ser secretario. Por ello me inclino a creer que la datación de la copia pudiera ser incorrecta.

Competencia esencial de esta Junta de Socorros habría de ser determinar quiénes quedaban exentos del pago del Catastro y a quiénes se les debería cobrar. Asimismo, le correspondía distribuir los recursos procedentes de los Expolios y Vacantes, a los que se podrían añadir todo cuanto se obtuviera de limosnas y donativos a solicitar, entre los damnificados de todos los pueblos «conforme a las necesidades de cada familia». En este sentido, la Junta era autónoma para resolver cualquier asunto mediante votación, con la obligación única de rendir mensualmente cuentas de las entradas y salidas de caudales.

En última instancia, la resolución concedía permiso para poder construir casas extramuros de Tortosa, pero a suficiente distancia de las murallas; circunstancia que había de ser vigilada por el gobernador y el ingeniero de la ciudad. Respecto de las poblaciones de Alfara, Garcia y Vinebre, de las que se decía «que aunque no han sido inundados han

74. El Ayuntamiento de Tortosa al barón de La Linde, Tortosa, 3 de noviembre de 1787, AHN, Consejos, legajo 23587, ff. $51-52$.

75. Memorias de la Sociedad Económica, 1787, IV: 372. 
padecido mucho», se les eximía del pago de ciertas cantidades a cuenta del Catastro previo examen de la Junta. Desde luego, en lo que hace a Vinebre no era cierto lo que se indicaba. Una relación de daños elaborada por su baile, Miguel Juan Martí, y remitida al intendente de Cataluña a través del gobernador de Tarragona, evidencia que el pueblo padeció «estragos y considerables daños [...] por las fuertes avenidas del río Ebro». Cerca de setenta casas asoladas y una estimación de las pérdidas — «según cálculo prudente»— en torno a 25.000 libras. $^{76}$

Vista la resolución real, la ciudad de Tortosa, tras el minucioso e insistente trámite administrativo iniciado nada más producirse el desastre, obtuvo las tres «mercedes» que solicitó a Carlos III para poder resarcir a sus vecinos de las pérdidas e iniciar el proceso de reconstrucción de la ciudad, arrabales, huerta y todas las infraestructuras arruinadas. Pero para «resolver» era necesaria una «propuesta» la cual, habría de partir del Consejo de Castilla. De ahí que surja la duda sobre la fecha de expedición de la comentada resolución, porque el trámite administrativo jamás detuvo su curso y, desde febrero de 1788, continuaban circulando escritos entre ayuntamiento, capitán general y Consejo de Castilla.

Así, el 10 de abril de 1788, el conde del Asalto en su calidad de presidente del Real Acuerdo, y tras informarse «convenientemente», apoyaba sin reservas las solicitudes de la ciudad de Tortosa y consideraba a sus vecinos merecedores de la compasión real en lo relativo a exención de tributos. También aceptaba la procedencia de los caudales para constituir el fondo de socorros por entender que eran

[...] los más adaptables y menos gravosos [...]; especialmente los dos primeros sí merecen la Real aprobación de V. M., pues con estos alivios, atendiendo los adelantos [...] que va haciendo aquella ciudad es de esperar que vaya poco a poco recuperando su antecedente esplendor. A que contribuirá esta Audiencia por quantos caminos le sugiera su amor a la felicidad pública y al mejor servicio de V. M. ${ }^{77}$

El 12 de abril se dirigía copia del escrito comentado líneas atrás al escribano de cámara del Consejo para los asuntos de la corona de Aragón ${ }^{78}$ y el 18, tras ser examinado por la sala de gobierno presidida por Campomanes, era remitido al fiscal del Consejo para que lo incorporara al expediente sobre la inundación de Tortosa y emitiera el correspondiente dictamen, el cual no llegaría hasta el 9 de junio.

Una lectura pausada de este documento produce sensaciones de muy variada índole. ${ }^{79}$ De entrada, el fiscal — probablemente el valenciano Manuel Sisternes y Felíu- (Molas 2001: $27)^{80}$ rebajaba de un modo sorprendente «las resultas del funesto suceso» considerando

76. D. Gaspar Bracho y Bustamante, gobernador de Tarragona, al Exmo. Sr. conde del Asalto, Tarragona, 7 de noviembre, de 1787, AHN, Consejos, legajo 23587, ff. 94-95.

77. El conde del Asalto y el Real Acuerdo al Rey, Barcelona, 10 de abril de 1788, AHN, Consejos, legajo 23587, ff. $146-147$.

78. El conde del Asalto a D. Juan Antonio Rero y Peñuelas, Barcelona, 12 de abril de 1788, AHN, Ibíd., f. 48.

79. Informe del Fiscal del Consejo de Castilla, Madrid, 9 de junio de 1788, AHN, Ibíd., ff. 150-152.

80. Según indica Pere Molas, Manuel Sisternes murió el 20 de junio de 1788 con lo que, probablemente, pudo redactar el dictamen. Le sustituyó José Antonio Fita. 
que fueron «menos desgraciadas [de lo] que podían prometerse» como consecuencia de la «extraordinaria avenida y tempestad de lluvias», con la «circunstancia de la hora tenebrosa de la noche». Puede que esta afirmación viniera provocada porque ya habían transcurrido nueve meses desde el terrible suceso, y la ciudad se recuperaba a un ritmo razonable gracias a que las providencias tomadas por los responsables políticos de Tortosa habían sido «vivas, eficaces y acertadas», plenas de «ardor y presteza», y, pese a la gran dimensión del desastre, consideraba un éxito que «solo» hubieran fallecido 98 personas en la Huerta y poblaciones inmediatas. La realidad, sin embargo, era distinta: los fallecidos doblaron esa cifra.

En sus preliminares el fiscal, teniendo como base el último informe del Real Acuerdo, entendía que ya se había «salido de aquel grande apuro», que las cosas se hallaban «en otro estado bien diferente» y que ya se podían disponer los remedios oportunos para que se restableciera la normalidad. Aceptaba las propuestas del ayuntamiento y le aconsejaba que, en lo tocante a la reparación de caminos, reclamara sus derechos por la vía correspondiente. Igualmente recomendaba que, para la construcción o reconstrucción de casas y edificios del común, cada población había de exponer sus previsiones. Pero lo que más importaba era el «alivio y socorro» de los vecinos, atendiendo a sus diferentes oficios -labradores, artesanos y menestrales- «según su respectiva necesidad, habilidad y facultades».

En general, su razonamiento descansaba en la convicción de que, con el buen hacer de los responsables municipales, no sería difícil que las gentes fueran recuperándose de las pérdidas padecidas de manera progresiva hasta alcanzar el «estado» del que gozaban antes de la catástrofe. Ello le conducía a conclusiones de difícil comprensión como, por ejemplo, cuando afirma textualmente:

El perjuicio de los pobres jornaleros habrá sido momentáneo y podrá resarcirse; y aún el de los artesanos, con la proporción del trabajo que han de facilitarles las mismas ruinas y desgracias acaecidas. ${ }^{81}$

Sin embargo, en lo esencial, el dictamen resultaba favorable a las solicitudes de la ciudad y sugería se aplicarán medidas de gracia apelando a la proverbial bondad del monarca. Así, entendía que la exención de las reales contribuciones solicitada constituía una gracia cuya «necesidad obligaba a su concesión», por lo que recomendaba al rey exonerar del gravamen a los afectados por el tiempo que considerara oportuno.

También creía acertada la creación de un fondo destinado a «socorrer la indigencia de labradores y artesanos a proporción de sus necesidades». Como los caudales solicitados para este fin pertenecían a los Expolios y Vacantes de la mitra tortosina, el fiscal entendía que resultaba necesaria la consulta previa al rey, pero, precisamente, para inclinar «su real ánimo a que las circunstancias de fomentar a aquellos vecinos [...] exigen la expedición de este arbitrio que se considera como único». Remataba su recomendación con un argumento fácilmente comprensible: el dinero de Expolios y Vacantes había salido de los mismos bolsillos que habían «de conseguir el alivio». No obstante, recomendaba a la Audiencia que, por medio del Real Acuerdo, se informara con mayor detalle de este asunto y que proce-

81. Informe del Fiscal del Consejo de Castilla, Madrid, 9 de junio de 1788. 
diera igualmente a formar Juntas de Caridad con arreglo a lo establecido en la Real Cédula de 3 de febrero de 1785. Respecto de la construcción de nuevas casas, coincidía con el ayuntamiento en que se llevaran a cabo en «solares nuevos, fuertes y proporcionados», bajo la supervisión de la Audiencia y el visto bueno del gobierno militar al ser Tortosa plaza fuerte.

El dictamen concluía con la recomendación de que se agradeciera, por separado, a todos aquellos que se habían distinguido en socorrer a los damnificados: «gobernantes, reverendo obispo y cabildo eclesiástico». Firmado, como se ha indicado, el 9 de junio, el documento pasó a la sala de gobierno y fue examinado por el conde de Campomanes, gobernador del Consejo de Castilla, y los consejeros Bendicho, Espinosa, Vallejo y Mendieta. Tras su aprobación fue remitido el día 12 de ese mismo mes a José Ruiz de Celada, relator de la sala. Lamentablemente, este grueso expediente referido al desastre de Tortosa de octubre de 1787, no contiene más documentación. Cabe pensar, no obstante, que, según el proceder habitual, se cursarían las correspondientes órdenes a todas las partes comunicando la resolución.

El resumen cuantificado de la desgracia arrojaba cifras muy significativas para Tortosa y las poblaciones del curso bajo del Ebro. Cascos urbanos arrasados, huertas y campos de cultivo arruinados, redes de riego y de comunicación impracticables, varios miles de personas acogidas en precario en diferentes alojamientos, más de 1.000 casas destruidas, 183 fallecidos y unas pérdidas globales de 2.672 .576 libras, de las que 1.428 .851 correspondían a la ciudad de Tortosa, arrabales y huerta y las restantes, hasta completar el monto total, a las poblaciones de la Ribera del Ebro (cuadros 2 y 3 ).

\section{A modo de conclusión}

En cualquier caso, y de este modo, se cerraban los trámites iniciados por el ayuntamiento tortosino apenas día y medio después de que el río Ebro se desbordara sobre la ciudad coincidiendo con la descarga de un violento temporal de lluvia y viento y provocara la conocida como riuada grossa. Pese a las dificultades propias del momento, agravadas constantemente por el devenir de los acontecimientos, los responsables políticos de Tortosa, con la ayuda de los vecinos y de las instituciones religiosas y civiles locales y del Principado, afrontaron con decisión el desastre y, aunque sin duda hubo algo de imprevisión, mantuvieron una frenética actividad para conseguir que todas las instancias políticas implicadas estuvieran permanentemente informadas de la evolución de los acontecimientos, sin descuidar en ningún momento la asistencia de sus vecinos. En poco más de seis meses, si atendemos la fecha de la Real Orden, de marzo de 1788 - o nueve, según el dictamen del fiscal-, se sustanciaba una auténtica declaración de zona catastrófica y se dictaban medidas que, en el contexto de la época, eran las esperadas; aunque no siempre se concedieran. El hecho de que esta desgracia coincidiera prácticamente en el tiempo con otra de dimensiones mayores, si cabe, como fue la de Sangüesa pudo haber sido motivo sobrado para no aprontar más recursos. 
Las cifras globales de la desgracia son suficientemente elocuentes y, en general, no difieren excesivamente al cotejar las referencias cronísticas, impresos de época y estudios más recientes que, en buena medida, toman sus referencias de los segundos. Estos impresos parecen responder, en su mayoría, a copias de la documentación oficial que he manejado o a comunicaciones efectuadas entre particulares. Un ejemplo: la crónica que publicó del suceso el Memorial Literario en su entrega del mes de octubre de 1787 se había elaborado, según se indicaba, extractando los datos de una carta que el trinitario calzado fray Tomás Ortiz había remitido al doctor José Ignacio Serrano, protomédico de los Reales Hospitales General y de la Pasión de la villa de Madrid. ${ }^{82}$ Dejo para otra ocasión el cotejo cuidadoso de todo ello puesto que el suceso lo merece, aunque por motivos de espacio ahora me resulta imposible. También pospongo el análisis de los remedios «espirituales» que se pusieron en marcha desde el mismo comienzo de la tragedia y que culminarían con la publicación, al año siguiente, de sermones de carácter panegírico hacia Carlos III (Pelfort 1788) o de claro contenido providencialista y, en consecuencia, amenazante para los desdichados vecinos de Tortosa (Aparicio 1788). En última instancia queda pendiente, asimismo, el análisis de las propuestas que, en materia de prevención de nuevos desastres como el aquí estudiado, se publicaron —con escaso éxito, por cierto- años después; así como el impacto que dejó en una Tortosa apenas recuperada de la tragedia de octubre de 1787, una nueva riada del Ebro a comienzos de septiembre de 1788.

\section{Bibliografía}

Alberola Romá, A. (1999). Catástrofe, economía y acción política en la Valencia del siglo XVIII. Valencia: Institució Alfons el Magnànim.

Alberola Romá, A. (2009). «La natura desfermada. Al voltant de manuscrits, impresos i imatges sobre desastres naturals en l'Espanya del segle xviI». En A. Alberola y J. Olcina (eds.). Desastre natural, vida cotidiana y religiosidad popular en la España moderna y contemporánea. Alicante: Publicacions de la Universitat d'Alacant, pp. 17-76.

Alberola Romá, A. (2010). Quan la pluja no sap ploure. Sequeres i riuades al País Valencià en l'Edat Moderna. Valencia: Publicacions de la Universitat de València.

Alberola Romá, A. (2019a). «No hay resistencia contra el poder de los elementos enfurecidos: el terratrèmol de Montesa-Estubeny del 1748». En E. Guinot, F. AndrÉs, J. Cerdá y J. F. Pardo Molero (eds.). Santa María de Montesa. La orden militar del reino de Valencia (ss. XIV-XIX). Valencia: Publicacions de la Universitat de València, pp. 309323.

Alberola Romá, A. (2019b). «La huella de la catástrofe en la España moderna. Reflexión en torno a los terremotos de 1748 y 1755». En M. D. Lorenzo, M. Rodríguez y D. Marcilhacy (coords.). Historiar las catástrofes. México-París: Universidad Nacional Autónoma de México-Sorbonne Université, pp. 67-92

82. Memorial Literario, p. 273. 
Alberola Romá, A.; Box Amorós, M. (2014). «Sequía, temporales, y cosechas deficitarias en el nordeste peninsular: un apunte de las consecuencias del «mal año» de 1783 en algunos corregimientos aragoneses y catalanes». En AA. VV. Libro jubilar en homenaje al profesor Antonio Gil Olcina. Alicante: Instituto Interuniversitario de Geografía-Publicacions de la Universitat d'Alacant, pp. 845-860.

Alberola Romá, A.; García Acosta, V. (eds.) (2021a). La Pequeña Edad del Hielo a ambos lados del Atlántico: episodios climáticos extremos, terremotos, erupciones volcánicas y crisis. Alicante: Publicacions de la Universitat d'Alacant.

Alberola Romá, A.; García Acosta, V. (2021b). «Vaivenes climáticos en la península Ibérica y Nueva España en los años ochenta del siglo xviı. Entre la "anomalía Maldá” y los "ciclos de El Niño"». En A. Alberola Romá y V. García Acosta (eds.): La Pequeña Edad del Hielo a ambos lados del Atlántico: episodios climáticos extremos, terremotos, erupciones volcánicas y crisis. Alicante: Publicacions de la Universitat d'Alacant, pp. 55-94. Alberola Romá, A.; Pradells Nadal, J. (2012). «Sequía, inundaciones, fiebres y plagas en tierras aragonesas y catalanas (1780-1790)». En D. Bernabé y A. Alberola (eds.). Magistro et amico. Diez estudios en Homenaje al profesor Enrique Giménez López. Alicante: Publicaciones de la Universidad de Alicante, pp. 65-93.

Andútar Castillo, F. (2004). «Capitanes generales y capitanías generales en el siglo xviI», Revista de Historia Moderna, núm. 22, pp. 291-320.

APARICIO, V. (1788). Exbortación a los fieles, al principio de la devota Rogativa que hizo el Muy Ilustre Cabildo de la Santa Iglesia Cathedral, de la ciudad de Tortosa, expuesto el SS. Sacramento para aplacar la cólera divina en la tempestad y avenida impensada del Río Ebro, la noche del día 8 de Octubre de 1788. Hecha por el Dr. Don --, canónigo de la misma Iglesia. Tortosa: por Josef Cid.

Balasch, C.; Pino, D.; Ruiz Bellet, J. L.; Tuset, J.; Barriendos, M.; Castelltort, X. et al. (2019). «The extreme floods in the Ebro River basin since $1600 \mathrm{CE}$, Science of the Total Environment, núm. 646, pp. 645-660.

Baltar Rodríguez, J. F. (1996). «Notas sobre la introducción y desarrollo de la renta del papel sellado en la monarquía española (siglos xvi y xvIII)», Anuario de Historia del Derecho Español, núm. 66, pp. 519-560.

Barriendos, M. (1995). «La dinàmica climàtica de Tortosa (ss. XIV-XIX)», Recerca, núm. 93, pp. 53-70.

BARRIENDOS, M. (2005). «Variabilidad climática y riesgos climáticos en perspectiva histórica. El caso de Catalunya en los siglos XvIII-XIX», Revista de Historia Moderna, núm. 23, pp. 11-34.

Barriendos, M.; Gil Guirado, S.; Pino, D.; Tuset, J.; Pérez Morales, A.; Alberola, A. (2019). «Climatic and social factors behind the Spanish Mediterranean flood evento chronologies from documentary sources (14th-20th centuries)», Global and Planetary Change, núm. 182. DOI:10.1016/j.gloplacha.2019.102997.

BARRIENDOS, M.; LLASAT, C. (2009). «El caso de la anomalía Maldá en la cuenca mediterránea occidental (1760-1800): un ejemplo de fuerte variabilidad climática». En A. Alberola y J. Olcina (eds.). Desastre natural, vida cotidiana y religiosidad popular en la Es- 
paña moderna y contemporánea. Alicante: Publicacions de la Universitat d'Alacant, pp. 253-286.

BayerRi y Bertomeu, E. (1934-1960). Historia de Tortosa y su comarca. Vols. 3 (1935) y 8 (1960). Tortosa: Imprenta y Librería de Algueró y Baiges.

Benito, G.; Sánchez-Moya, Y.; Medialdea, A.; Barriendos, M.; Calle, M.; Rico, M. et al. (2020). «Extreme Floods in Small Mediterranean Catchments: Long-term response to climate variability and change». Water, núm. 12, 1008. DOI:10.3390/w12041008.

Bru i Borrás, F. M. (1955). Fulls d'Història de la vila de Tivissa i del seu territori antic. Tarragona: Aymá, S. L. [Hay reedición en facsímil del año 2010 a cargo del ayuntamiento de Tivissa con introducción de Ezequiel Gort i Juanpere].

CaSTelis, I. (1970). «Els rebomboris del pa de 1789 a Barcelona», Recerques, núm. 1, pp. 5181.

Escartín SÁnchez, E. (1980). «Los intendentes de Cataluña en el siglo xviII. Datos biográfiCos». En P. Molas Ribalta, P. (coord.). Historia social de la Administración española. Barcelona: Consejo Superior de Investigaciones Científicas, pp. 249-268.

Escartín SÁnchez, E. (1984). «El desacord del Reial Acord (1716-1755)», Pedralbes, núm. 4, pp. 113-146.

Fernández y Domingo, D. (1867). Anales o Historia de Tortosa, desde su fundación hasta nuestros dias [...]. Barcelona: Establecimiento tipográfico de Jaime Jepús, calle de Petrixol, núm. 14, principal.

FloRescano, E. (comp.) (1981). Fuentes para la historia de la crisis agrícola de 1785-1786. 2 vols. México D.F.: Archivo General de la Nación.

[García de ZAmora, M.] (1804). Riada de Tortosa del día 8 de octubre del año 1787 (1804). Barcelona: Oficina de Antonio Sastre.

García TorRes, A. (2016). «La difícil vuelta a la normalidad tras el desastre: las cicatrices de los temporales de 1751 en el Levante peninsular español», Tiempos modernos. Revista Electrónica de Historia Moderna, vol. 8, núm. 33, pp. 215-235.

GarCíA ToRRES, A. (2018). Riesgo climático y desastre en tierras meridionales valencianas durante el siglo xVIII. Alicante: Publicacions de la Universitat d'Alacant.

García TorRes, A. (2011). «Tras la tempestad no llegó la calma: el Medio Vinalopó ante los temporales de septiembre de 1793", Revista de Historia Moderna, núm. 29, pp. 103-120.

GimÉnez López, E. (2004). «Marte y Astraea en la Corona de Aragón. La preeminencia de los capitanes generales sobre los togados en los primeros años de la Nueva Planta», Revista de Historia Moderna, núm. 22, pp. 251-269.

Irles Vicente, M. C. (2003). «Los extranjeros en la administración corregimental española del siglo xviI». En M. B. Viliar García y P. Pezzi Cristóbal (eds.). I Coloquio Internacional: Los extranjeros en la España Moderna. Tomo 2. Málaga: Ministerio de Ciencia e Innovación, pp. 439-450.

Mas GaLvañ, C. (1988). «De la Ilustración al liberalismo: el Seminario de San Fulgencio de Murcia (1774-1823)», Trienio. Ilustración y Liberalismo, núm. 12, pp. 102-175.

MEMORIAS DE LA SOCIEDAD ECONÓMICA (1787). Tomo 4. Madrid: don Antonio Sancha, Impresor de la Real Sociedad. 
MerCader, J. (1957). Els capitans generals, segle XVIII. Barcelona: Teide.

Merino, J. P. (1981). La Armada española en el siglo xVIII. Madrid: Fundación Universitaria Española.

Miravall, R. (1997). Flagells naturals sobre Tortosa. Riuades, gelades, aiguats $i$ sequeres, ventades $i$ terratrèmols. Barcelona: Columna Edicions.

Molas i Ribalta, P. (2001). «Aragón en el Consejo de Castilla», Cuadernos dieciochistas, núm. 2, pp. 13-35.

Moxó, S. DE (1959). «Un medievalista en el Consejo de Hacienda: don Francisco Carrasco; marqués de la Corona (1715-1791)», Anuario de Historia del Derecho Español, núm. 29, pp. 609-668.

MuÑoz y SEBASTIÁ, J. H. (2014-2015). «Dues relacions inèdites sobre les riuades dels anys 1743 i 1787 a la ciutat de Tortosa», Butlletí Arqueològic, vol. 5, núm. 36-37, pp. 249-262.

O'Callaghan, R. (1886). Anales de Tortosa e historia de la santa Cinta. Por el Dr. D. --, canónigo doctoral de la santa iglesia catedral de Tortosa. Tortosa: Imprenta Católica de Gabriel Llasat, Bou, 16.

Ollero, A. (1996). El curso medio del Ebro: geomorfología fluvial, ecogeografía y riesgos. Zaragoza: Publicaciones del Consejo de Protección de la Naturaleza de Aragón.

Ozanam, D. (1992). Les intendants espagnols du xvir eiècle. Madrid: Casa de Velázquez. PELFORT, J. (¿1788?). Sermón que en los solemnes cultos que dedicó a la Divina Magestad la Exemplar, y Fidelisima Ciudad de Tortosa, en acción de gracias, por el alivio recibido de la piadosa munificiencia de nuestro Catbolico Monarca CARLOS TERCERO (QUE DIOS GUARDE) para el restablecimiento de lo perdido en la estupenda avenida del Ebro en los días ocho y nueve de octubre de 1787, predicó en el día 20 de Abril de 1788 en la Santa Iglesia de Tortosa el DOCTOR DON JAIME PELFORT CATEDRATICO que fue de Filosofía y Sagrada Theologia y Rector del Real Colegio de San Carlos, en la Pontifica y Real Universidad de Cervera y en el día Canónigo de dicha Santa Iglesia, Examinador Sinodal del presente Obispado, e individuo de la Real Academia de Buenas Letras de Barcelona. Tortosa: por Josef Cid, calle de la Rosa.

Pérez SAmper, M. Á. (1996). «Magistrados y capitanes generales. Civilismo frente a militarismo en Cataluña a finales del siglo xviI». En J. L. Castellano (ed.). Sociedad, administración y poder en la España del Antiguo Régimen. Granada, pp. 315-353.

Querol Coll, E. (2006). «Les riuades de l'Ebre a la literatura». Recerca, núm. 10, pp. 261-300. ROCAFORT, J. [1762-1818] (1945). Libro de cosas notables sucedidas en esta villa de Castellón de la Plana desde 1762. Edición y notas de E. Codina Armengot. Castellón de la Plana: Sociedad Castellonense de Cultura-Ayuntamiento de Castellón de la Plana.

Sabaté i Margalef, F.; Nulla i Agulla, J. (1988). «Exempció de la contribució als pobles afectats per la riuada de l'Ebre l'any 1787». Pedralbes, núm. 8-I, pp. 573-580.

SAmbricio, C. (1991). Territorio y ciudad en la España de la Ilustración. Madrid: MOPTInstituto del Territorio y Urbanismo.

Villanueva, J. L. (1806). Viage literario a las iglesias de España. Le publica con algunas observaciones don --, capellán de honor de S. M. y penitenciario de su Real Capilla. Tomo 5. Madrid: Imprenta Real. 